\title{
Preclinical Evaluation of AZ12601011 and AZ12799734, Inhibitors of Transforming Growth Factor $\beta$ Superfamily Type 1 Receptors
}

\author{
Lindsay C. Spender, ${ }^{1}$ G. John Ferguson, ${ }^{2}$ Gareth D. Hughes, Barry R. Davies, \\ Frederick W. Goldberg, Blanca Herrera, ${ }^{3}$ Richard G. Taylor, Lauren S. Strathearn, \\ Owen J. Sansom, Simon T. Barry, and (1) Gareth J. Inman
}

\begin{abstract}
Cancer Research UK Beatson Institute, Garscube Estate, Bearsden, Glasgow, United Kingdom (L.C.S., G.J.F., B.H., O.J.S., G.J.I.); Institute of Cancer Sciences, University of Glasgow, Glasgow, United Kingdom (O.J.S., G.J.I.) Division of Cellular Medicine, School of Medicine, University of Dundee, Dundee, United Kingdom (R.G.T., L.S.S.); and AstraZeneca Bioscience, Oncology (G.D.H., S.T.B., B.R.D.) and Medicinal Chemistry, Oncology (F.W.G.), IMED Biotech Unit, AstraZeneca, Cambridge, United Kingdom
\end{abstract}

Received May 7, 2018; accepted November 8, 2018

\section{ABSTRACT}

The transforming growth factor $\beta$ (TGF $\beta$ ) superfamily includes $\operatorname{TGF} \beta$, activins, inhibins, and bone morphogenetic proteins (BMPs). These extracellular ligands have essential roles in normal tissue homeostasis by coordinately regulating cell proliferation, differentiation, and migration. Aberrant signaling of superfamily members, however, is associated with fibrosis as well as tumorigenesis, cancer progression, metastasis, and drug-resistance mechanisms in a variety of cancer subtypes. Given their involvement in human disease, the identification of novel selective inhibitors of TGF $\beta$ superfamily receptors is an attractive therapeutic approach. Seven mammalian type 1 receptors have been identified that have context-specific roles depending on the ligand and the complex formation with the type 2 receptor. Here, we characterize the biologic effects of two transforming growth factor $\beta$ receptor 1 (TGFBR1) kinase inhibitors designed to target TGF $\beta$ signaling. AZ12601011 [2-(2-pyridinyl)-4-(1H-pyrrolo[3,2-c]pyridin-1-yl)6,7-dihydro-5H-cyclopenta[d]pyrimidine]; structure previously undisclosed] and AZ12799734 [4-(\{4-[(2,6-dimethyl-3-pyridinyl) oxy]-2-pyridinyl\}amino)benzenesulfonamide] $\left({ }^{\prime} \mathrm{C}_{50}=18\right.$ and $47 \mathrm{nM}$, respectively) were more effective inhibitors of $\operatorname{TGF} \beta$-induced reporter activity than SB-431542 [4-[4-(1,3-benzodioxol-5-yl)-5(2-pyridinyl)-1H-imidazol-2-yl]benzamide] $\left(\mathrm{IC}_{50}=84 \mathrm{nM}\right)$ and LY2157299 [4-[2-(6-methylpyridin-2-yl)-5,6-dihydro-4Hpyrrolo[1,2-b]pyrazol-3-yl]quinoline-6-carboxamide monohydrate]] (galunisertib) $\left(\mathrm{IC}_{50}=380 \mathrm{nM}\right)$. AZ12601011 inhibited phosphorylation of SMAD2 via the type 1 receptors activin $A$ receptor type 1B (ALK4), TGFBR1, and activin A receptor type 1C (ALK7). AZ12799734, however, is a pan TGF/BMP inhibitor, inhibiting receptor-mediated phosphorylation of SMAD1 by activin $A$ receptor type $1 \mathrm{~L}$, bone morphogenetic protein receptor type $1 \mathrm{~A}$, and bone morphogenetic protein receptor type 1B and phosphorylation of SMAD2 by ALK4, TGFBR1, and ALK7. AZ12601011 was highly effective at inhibiting basal and TGF $\beta$-induced migration of $\mathrm{HaCaT}$ keratinocytes and, furthermore, inhibited tumor growth and metastasis to the lungs in a 4T1 syngeneic orthotopic mammary tumor model. These inhibitors provide new reagents for investigating in vitro and in vivo pathogenic processes and the contribution of $\mathrm{TGF} \beta$ - and BMP-regulated signaling pathways to disease states.

\section{Introduction}

The transforming growth factor $\beta$ (TGF $\beta$ ) cytokine superfamily, including TGF $\beta$, activin, inhibins, nodal and bone morphogenetic proteins (BMPs), regulates developmental and cellular biology to control and maintain tissue homeostasis. In different contexts, the interaction of the dimeric ligands with their cognate receptors activates intracellular signaling pathways to control cell death, survival, adhesion, differentiation,

B.R.D., G.D.H., F.W.G., and S.T.B. are employees and shareholders of AstraZeneca. G.J.F is an employee of an AstraZeneca-owned company and is a shareholder of AstraZeneca. This work was partially funded by AstraZeneca. L.C.S., G.J.I., G.J.F., and B.H. were supported by Cancer Research UK and Worldwide Cancer Research (International Fellowship to G.J.I. and 11-0788).

${ }^{1}$ Current affiliation: Division of Molecular and Clinical Medicine, School of Medicine, University of Dundee, Dundee, United Kingdom.

${ }^{2}$ Current affiliation: Department of Respiratory, Inflammation and AutoImmunity Research, MedImmune Limited, Cambridge, United Kingdom.

${ }^{3}$ Current affiliation: Department Biochemistry and Molecular Biology, Faculty of Pharmacy, Complutense University of Madrid, Health Research Institute of the Hospital Clínico San Carlos, Madrid, Spain.

https://doi.org/10.1124/mol.118.112946. movement, and deposition of components of the extracellular matrix (Shi and Massague, 2003). In human disease, the expression of, or cellular responses to, these factors may become deregulated. The resulting aberrant signaling can contribute to many disease pathologies, including cancer, fibrosis, atherosclerosis, and scarring (Blobe et al., 2000). $\mathrm{TGF} \beta$, for example, can switch from tumor suppressor to tumor promoter functions depending on epigenetic/genetic changes occurring in the tumor cell (Inman, 2011). Given their extensive role in human disease, the ligands, their receptors, and their downstream effectors are considered attractive therapeutic targets (Akhurst and Hata, 2012).

Cytokine signaling is initiated by the formation of heterotetrameric complexes of six polypeptides comprising dimeric ligands, two constitutively active type 2 receptors, and two type 1 receptors. Upon complex formation, the serine/ threonine kinase type 1 receptors are phosphorylated and activated by the type 2 receptors, which initiates a canonical signaling cascade involving the recruitment, phosphorylation, 
and activation of receptor-regulated SMADs. The phosphorylated SMADs bind to SMAD4, and the complexes accumulate in the cell nucleus where they both positively and negatively regulate gene expression. In addition, a number of SMAD-independent noncanonical signaling pathways (e.g., mitogen-activated protein kinases, Rho GTPases, and phosphoinostide-3-kinases) are also activated which impact on gene regulation and cellular responses (Zhang, 2009). Five type 2 and seven type 1 receptors have been identified in mammalian cells. Their specificity for ligand and receptor complex formation determines biologic outcome (Schmierer and Hill, 2007). For instance, TGF $\beta$ interacts primarily with transforming growth factor $\beta$ receptor 2 and the ubiquitous type 1 receptor, transforming growth factor $\beta$ receptor 1 (TGFBR1), to regulate cytostasis, apoptosis, and epithelial to mesenchymal transition, but both TGF $\beta$ and growth differentiation factor 2 (BMP9) may bind to the endothelial cell restricted type 1 receptor ACVRL1 to regulate angiogenesis. In some circumstances, $\operatorname{TGF} \beta$ may also signal via TGFBR1 and activin A receptor type 1 (ALK2) to induce SMAD1/5 phosphorylation and a subset of TGF $\beta$ inducible genes involved in epithelial to mesenchymal transition (Ramachandran et al., 2018). BMPs, meanwhile, bind selectively to BMPR2 and the type 1 receptors activin A receptor type 1L (ALK1), ALK2, bone morphogenetic protein receptor type 1A (BMPR1A), and bone morphogenetic protein receptor type 1B (BMPR1B) to regulate embryogenesis and bone formation (Wang et al., 2014). TGF $\beta$, activin, and nodal signal via TGFBR1, activin A receptor type $1 B$ (ALK4), and activin A receptor type 1C (ALK7), respectively, predominantly to phosphorylate and activate SMAD2 and SMAD3, whereas BMPs induce phosphorylation of SMAD1, SMAD5, and SMAD8.

Given the role of TGF $\beta$ in pathologic states, there have been numerous therapeutic approaches taken to blockade signaling, with some progressing through preclinical evaluation to clinical trial (Lahn et al., 2005; Akhurst and Hata, 2012). Some selective small-molecule inhibitors (SMIs) of the TGFBR1 kinase are well characterized (e.g., SB-431542, 4-[4-(1,3-benzodioxol5-yl)-5-(2-pyridinyl)-1H-imidazol-2-yl]benzamide) (Inman et al., 2002; Vogt et al., 2011) and have been used extensively in preclinical models to interrogate TGF $\beta$-regulated biological pathways. SMIs of TGFBR1 have shown therapeutic promise in models of fibrosis (Gellibert et al., 2006; Park et al., 2015a,b), and two TGFBR1 inhibitors are currently in clinical trials, vactosertib (N-(2-fluorophenyl)-5-(6-methyl-2-pyridinyl)4-[1,2,4]triazolo[1,5-a]pyridin-6-yl-1H-imidazole-2-methanamine) (TEW-7197) and galunisertib (LY2157299, 4-[2-(6-methylpyridin2-yl)-5,6-dihydro-4H-pyrrolo[1,2-b]pyrazol-3-yl]quinoline-6carboxamide monohydrate). The results of the first-in-human trials with vactosertib (ClinicalTrials.gov identifier: NCT02160106) are not yet reported. Galunisertib, however, has progressed despite some initial toxicity concerns and is now considered safe enough when administered with careful dosing schedules (Fujiwara et al., 2015; Herbertz et al., 2015; Kovacs et al., 2015) to allow further clinical development in cancer patients with unmet need. TGFBR1 inhibitors, therefore, remain attractive leads for drug development.

AZ12601011 2-(2-pyridinyl)-4-(1H-pyrrolo[3,2-c]pyridin-1yl)-6,7-dihydro-5H-cyclopenta[d]pyrimidine; structure previously undisclosed] and AZ12799734 [4-(\{4-[(2,6-dimethyl-3-pyridinyl)oxy]-2-pyridinyl\}amino)benzenesulfonamide] (Goldberg et al., 2009; Anderton et al., 2011) are two selective TGFBR1 inhibitors. AZ12601011 and AZ12799734 inhibit TGFBR1 kinase activity (competition binding) with $\mathrm{K}_{\mathrm{d}}$ values of 2.9 and $740 \mathrm{nM}$, respectively. Both compounds have some inhibitory activity against the related receptors ALK4 and BMPR1B but are only weakly active against ALK1, ALK2, and BMPR1A in in vitro kinase assays (Anderton et al., 2011). Here, we characterize their specificity and in vitro and in vivo biological activity in a variety of cell-based biochemical and functional assays in comparison with other well studied and clinically relevant TGFBR1 SMIs. We show that AZ12601011 is a selective inhibitor of ALK4, ALK7, and TGFBR1. Importantly, AZ12601011 inhibited TGF $\beta$-induced epithelial cell migration at 10-fold lower concentrations than galunisertib and was effective in an in vivo tumor model system. Additionally, we identify AZ12799734 as a pan BMP/TGF $\beta$ inhibitor providing a novel spectrum of singleagent inhibitory activity useful for analytical evaluation of TGF $\beta$ superfamily-regulated processes.

\section{Materials and Methods}

Synthetic procedures for AZ12799734 have been described previously [compound 19 (Goldberg et al., 2009)].

\section{Synthetic Procedures for AZ12601011}

2-Pyridin-2-yl-1,5,6,7-tetrahydrocyclopenta[e]pyrimidin-4-one2amidinopyridine hydrochloride $(7.88 \mathrm{~g}, 50 \mathrm{mmol})$ and $\mathrm{K}_{2} \mathrm{CO}_{3}(6.91 \mathrm{~g}$, $50 \mathrm{mmol}$ ) were added to methyl 2-oxocyclopentanecarboxylate (commercially sourced) $(6.21 \mathrm{~mL}, 50 \mathrm{mmol})$ in ethanol $(100 \mathrm{~mL})$. The mixture was heated to reflux for 5 hours. While the mixture was still hot, it was acidified by the addition of $2 \mathrm{M}$ aqueous $\mathrm{HCl}(20 \mathrm{~mL})$ and water $(30 \mathrm{~mL})$. The mixture was allowed to cool to room temperature overnight and was then partially concentrated in vacuo. The resulting precipitate was collected by filtration, washed with water and diethyl ether, and dried in vacuo to give the desired product. Additional product was obtained by concentrating the filtrate in vacuo and purifying the resulting residue by recrystallization from ethanol/water. The two batches were combined to afford the title compound ( $3.63 \mathrm{~g}, 34 \%)\left({ }^{1} \mathrm{H} \mathrm{NMR} \mathrm{d6-DMSO}\right): 2.04(2 \mathrm{H}$, quintet), $2.71(2 \mathrm{H}, \mathrm{t}), 2.88(2 \mathrm{H}, \mathrm{t}), 7.63(1 \mathrm{H}, \mathrm{dd}), 8.04(1 \mathrm{H}, \mathrm{t}), 8.30(1 \mathrm{H}, \mathrm{d})$, $8.73(1 \mathrm{H}, \mathrm{d}), \mathrm{NH}$ missing; $m / z \mathrm{MH}^{+} 214$ ):

\footnotetext{
ABBREVIATIONS: ALK1, activin A receptor type 1L; ALK2, activin A receptor type 1; ALK4, activin A receptor type 1B; ALK7, activin A receptor type 1C; AZ12601011, 2-(2-pyridinyl)-4-(1H-pyrrolo[3,2-c]pyridin-1-yl)-6,7-dihydro-5H-cyclopenta[d]pyrimidine; AZ12799734, 4-(\{4-[(2,6-dimethyl-3-pyridinyl)oxy]-2-pyridinyl\}amino)benzenesulfonamide; BMP, bone morphogenetic protein; BMPR1A, bone morphogenetic protein receptor type 1A; BMPR1B, bone morphogenetic protein receptor type 1B; BSA, bovine serum albumin; CST, Cell Signaling Technology; d, doublet; dd, doublet of doublets; DMEM, Dulbecco's modified Eagle's medium; DMSO, dimethylsulfoxide; EGF, epidermal growth factor; ERK, extracellular signal-regulated kinase; FBS, fetal bovine serum; G418, (2R,3R,4R,5R)-2-[(1S,2S,3R,4S,6R)-4,6-diamino-3-[(2S,3R,4R,5S,6R)-3-amino-4,5-dihydroxy-6-[(1R)-1-hydroxyethyl] oxan-2-yl]oxy-2hydroxycyclohexyl]oxy-5-methyl-4-(methylamino)oxane-3,5-diol; LY2157299, 4-[2-(6-methylpyridin-2-yl)-5,6-dihydro-4H-pyrrolo[1,2-b]pyrazol-3-yl]quinoline-6-carboxamide monohydrate; MAPK, mitogen-activated protein kinase; MEK, Mitogen-activated protein kinase kinase; PBS, phosphate-buffered saline; SB-431542, 4-[4-(1,3-benzodioxol-5-yl)-5-(2-pyridinyl)-1H-imidazol-2-yl]benzamide; SB-525334, 6-[2-(1,1-Dimethylethyl)-5-(6-methyl-2-pyridinyl)1H-imidazol-4-yl]quinoxaline; SMI, small-molecule inhibitor; t, triplet; TEW-7197, N-(2-fluorophenyl)-5-(6-methyl-2-pyridinyl)-4-[1,2,4]triazolo[1,5-a]pyridin6 -yl-1H-imidazole-2-methanamine; TGF $\beta$, transforming growth factor $\beta$; TGFBR1, transforming growth factor $\beta$ receptor 1 ; U0126, 1,4-Diamino-2,3dicyano-1,4-bis[2-aminophenylthio]butadiene.
} 
<smiles>O=c1nc(-c2ccccn2)[nH]c2c1CCC2</smiles>

4-Chloro-2-pyridin-2-yl-6,7-dihydro-5H-cyclopenta[d]pyrimidine phosphoryl chloride ( $4.72 \mathrm{~mL}, 50.7 \mathrm{mmol}$ ) was added to 2-pyridin-2-yl1,5,6,7-tetrahydro-cyclopenta[e]pyrimidin-4-one ( $2.7 \mathrm{~g}, 12.7 \mathrm{mmol})$. The mixture was heated at reflux for 1 hour and was then cooled to room temperature. The mixture was concentrated in vacuo and extracted with $\mathrm{CH}_{2} \mathrm{Cl}_{2} / \mathrm{CH}_{3} \mathrm{OH}$. The organic layer was washed sequentially with $5 \%$ aqueous $\mathrm{NaOH}$ and sat. brine, then dried $\left(\mathrm{MgSO}_{4}\right)$ and concentrated in vacuo to afford the title compound $(2.60 \mathrm{~g}, 89 \%)$ as a solid $\left[{ }^{1} \mathrm{H}\right.$ NMR $\left(\mathrm{DMSO}-d^{6}\right) 2.20(2 \mathrm{H}$, quintet), $3.06(2 \mathrm{H}, \mathrm{t}), 3.16(2 \mathrm{H}, \mathrm{t}), 7.79(1 \mathrm{H}, \mathrm{t}), 8.27$ $\left.(1 \mathrm{H}, \mathrm{dt}), 8.53(1 \mathrm{H}, \mathrm{d}), 8.82(1 \mathrm{H}, \mathrm{d}) ; m / z \mathrm{MH}^{+} 232\right]$ :<smiles>Clc1nc(-c2ccccn2)nc2c1CCC2</smiles>

AZ12601011, 5-azaindole (1.32 g, $11.1 \mathrm{mmol}), \mathrm{Cs}_{2} \mathrm{CO}_{3}(6.05 \mathrm{~g}$, $18.6 \mathrm{mmol})$, palladium(II) acetate $(0.125 \mathrm{~g}, 0.56 \mathrm{mmol})$, and $(R)-(-)-1-[(S)-$ 2-(dicylohexylphosphino)ferrocenyl]ethyldi-tert-butylphosphine $(0.644 \mathrm{~g}$, $1.11 \mathrm{mmol}$ ) were added to 4-chloro-2-(pyridin-2-yl)-6,7-dihydro-5Hcyclopenta $[d]$ pyrimidine $(2.15 \mathrm{~g}, 9.28 \mathrm{mmol})$ in 1,4-dioxane $(46.4 \mathrm{~mL})$, and the mixture was heated at reflux for 3 hours. The mixture was allowed to cool to room temperature and then concentrated in vacuo to give a brown gum which was partitioned between $\mathrm{CH}_{2} \mathrm{Cl}_{2} /$ water. The organic layer was isolated and dried $\left(\mathrm{MgSO}_{4}\right)$ and concentrated in vacuo. The resulting crude mixture was purified by flash column chromatography, eluting with $0 \%-5 \% \mathrm{CH}_{3} \mathrm{OH}$ in $\mathrm{CH}_{2} \mathrm{Cl}_{2}$, to afford the title compound $(1.44 \mathrm{~g}, 50 \%)$ as a solid [ ${ }^{1} \mathrm{H}$ NMR (DMSO- $\left.d^{6}\right) 2.21(2 \mathrm{H}$, quintet), 3.15 ( $2 \mathrm{H}, \mathrm{t}), 3.28-3.34(2 \mathrm{H}, \mathrm{m}), 7.01(1 \mathrm{H}, \mathrm{dd}), 7.58(1 \mathrm{H}, \mathrm{dq})$, $8.01-8.06(2 \mathrm{H}, \mathrm{m}), 8.45(1 \mathrm{H}, \mathrm{d}), 8.46(1 \mathrm{H}, \mathrm{dt}), 8.65(1 \mathrm{H}, \mathrm{dt}), 8.84(1 \mathrm{H}$, $\left.\mathrm{dq}), 9.00(1 \mathrm{H}, \mathrm{d}) ; m / z \mathrm{MH}^{+} 314\right]$ :

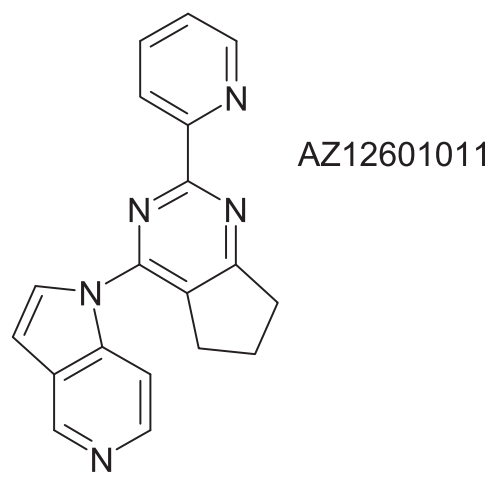

Plasmids. Plasmids expressing SMAD1 and SMAD2 and constitutively active ALK1, ALK2, BMPR1A, ALK4, TGFBR1, BMPR1B, and ALK7 used in transient transfections have been described previously (Inman et al., 2002).

Cell Culture. HaCaT, C2C12, T47D, VU-SCC-040, NIH3T3, NIH3T3-CAGA12-luc, C2C12-BRE-luc, and murine 4T1 [4T1-Luc (RRID:CVCL_J239)] cell lines were maintained in Dulbecco's modified Eagle's medium (DMEM) supplemented with $10 \%$ fetal bovine serum (FBS) and glutamine. Medium for NIH3T3-CAGA12-luc cells was also supplemented with $400 \mathrm{mg} / \mathrm{mL}$ G418 ((2R,3R,4R,5R)-2[(1S,2S,3R,4S,6R)-4,6-diamino-3-[(2S,3R,4R,5S,6R)-3-amino-4,5-dihydroxy6-[(1R)-1-hydroxyethyl]oxan-2-yl]oxy-2-hydroxycyclohexyl]oxy-5-methyl4-(methylamino)oxane-3,5-diol), and medium for C2C12-BRE-luc was supplemented with $700 \mathrm{mg} / \mathrm{mL}$ G418. All cell lines were confirmed negative for mycoplasma contamination by the Institute's mycoplasma testing service. Cells were exogenously stimulated with TGF $\beta 1$ (PeproTech EC, Ltd. London, U.K.) resuspended in $1 \mathrm{mg} / \mathrm{mL}$ bovine serum albumin (BSA)/4 $\mathrm{mM} \mathrm{HCl}$. Inhibitors were diluted in DMSO at 1000-2000 $\times$ final concentration required. Appropriate BSA/ $\mathrm{HCl}$ and DMSO vehicle controls were used throughout. Osmotic shock was induced by treatment of cells for 20 minutes with $0.7 \mathrm{M} \mathrm{NaCl}$ prepared in DMEM and was used to induce p38 mitogen-activated protein kinase (MAPK) phosphorylation (Davis, 2000). Epidermal growth factor (EGF) treatment was carried out by exogenous addition of $30 \mathrm{ng} / \mathrm{mL}$ EGF for 5 minutes. The MEK1/2 (Mitogen-activated protein kinase kinase) inhibitor U0126 [1,4-Diamino-2,3-dicyano-1,4bis[2-aminophenylthio]butadiene] (Tocris, Bristol, UK) was used at a concentration of $25 \mu \mathrm{M}$.

C2C12-BRE-Luciferase and NIH3T3-CAGA12-Luciferase Reporter Bioassays. The C2C12-BRE-luciferase (Herrera and Inman, 2009) and NIH3T3-CAGA12-luciferase stable cell lines (Spender et al., 2016) used in the bioassays have been described previously. Cells were seeded overnight at $1 \times 10^{4} /$ well in 96 -well plates. Cells were then pretreated for 20 minutes with a titration of SB-431542 (Inman et al., 2002) (Tocris), SB-525334 [6-[2-(1,1-Dimethylethyl)-5-(6-methyl-2pyridinyl)-1H-imidazol-4-yl]quinoxaline] (Sigma-Aldrich, St. Louis, MO), AZ12601011 (Anderton et al., 2011), AZ12799734 (AstraZeneca, Cambridge, UK), or LY2157299 (galunisertib; Selleck, Houston, TX) followed by stimulation with exogenous TGF $\beta(1 \mathrm{ng} / \mathrm{mL})$ or BMPs. Cell lysates were analyzed by the Luciferase Assay system (Promega, Madison, WI) as recommended by the manufacturer. The mean percentage activity $( \pm$ S.D.) of the reporter in the presence of the inhibitors relative to maximal activation induced by TGF $\beta$ or BMPs $(100 \%)$ is shown.

Dose-Response $I_{50}\left(D_{m}\right)$ Calculation and Proliferation Curve Analysis. IC $_{50}$ values were determined by curve fitting using either nonlinear regression (GraphPad Prism 7; GraphPad Software, La Jolla, CA) or CalcuSyn Version 2.11 software (Biosoft, Cambridge, $\mathrm{UK})$, which reports median-effect plots, the median dose $\left(\mathrm{D}_{\mathrm{m}}, \mathrm{IC}_{50}\right)$, and the correlation coefficient $(\mathrm{r})$. The $95 \%$ confidence intervals of $\mathrm{IC}_{50}$ were determined using GraphPad Prism 7 software. Statistical analysis of cell proliferation curves was carried out by pairwise comparison between two or more groups of growth curves using the compareGrowthCurves function from statmod (R Project, The R Foundation, Vienna, Austria). The number of permutations (nsim) was 10,000, and $P$ values given were adjusted for multiple testing.

Western Blotting and Antibodies. Cell lysates were analyzed by SDS-PAGE using the following antibodies: phospho-SMAD2 (Ser465/467) [rabbit polyclonal, \#3101; Cell Signaling Technology (CST), Danvers, MA], phospho-SMAD1 (rabbit polyclonal, \#9511; CST), phospho-extracellular signal-regulated kinase [ERK; rabbit polyclonal phospho p44/42 (Thr202/Tyr204) MAPK, \#9101; CST], phospho-p38 (Thr180/Tyr182) (rabbit polyclonal, \#9211; CST), SMAD1 (rabbit polyclonal \#38-5400; Zymed, Paisley, UK), SMAD2 (mouse monoclonal, C16D3; CST), and SMAD2/3 (mouse monoclonal, Clone 18; BD Transduction Laboratories, Wokingham, UK). Secondary horseradish peroxidase-conjugated antibodies (Dako, Stockport, UK) and enhanced chemiluminescence (GE Healthcare, Chicago, IL) were used to detect bound antibody. LI-COR (Cambridge, UK) infrared imaging was carried out using a LI-COR Odyssey system following 
TABLE 1

Mass spectrometer and ultrahigh-performance liquid chromatography system parameters

\begin{tabular}{ll}
\hline & Parameter \\
\hline Mass spectrometer & Waters (Milford, MA) Ultima Pt \\
HPLC system & Agilent (Santa Clara, CA) 1100 HPLC \\
Column & Waters x-bridge C18 50 $\times 2.1,3.5 \mathrm{u}$ \\
Solvent A & $95 \%$ water, 5\% MeOH + 10 mM ammonium acetate \\
Solvent B & $95 \% \mathrm{MeOH}, 5 \%$ water + $10 \mathrm{mM}$ ammonium acetate \\
Gradient & \\
Time (min) & \\
0 & $95 \% \mathrm{~A}, 5 \% \mathrm{~B}$ \\
3 & $5 \% \mathrm{~A}, 95 \% \mathrm{~B}$ \\
3.8 & $95 \% \mathrm{~A}, 5 \% \mathrm{~B}$ \\
3.81 & $95 \% \mathrm{~A}, 5 \% \mathrm{~B}$ \\
4 & $0.75 \mathrm{~mL} / \mathrm{min}$ \\
Flow & $4 \mathrm{~min}$, use a divert valve for initial $0.5 \mathrm{~min}$ \\
Run time &
\end{tabular}

HPLC, high-performance liquid chromatography.

western blotting using rabbit monoclonal anti-phospho-SMAD2 (Ser465/ 467, 138D4, \#3108; CST) and mouse monoclonal pan-SMAD2 antibody (L16D3, \#3103; CST). Secondary antibodies were IRDye 680RD donkey (polyclonal) anti-rabbit IgG (H+L, \#925-68073; LI-COR) and IRDye 800CW goat anti-mouse IgG (H+L, \#926-32210; LI-COR). Analysis of signal intensities was carried out using LI-COR Image Studio version 4.0.21 software. Signal was normalized to pan-SMAD2 levels measured on channel 800 according to the manufacturer's signal protein normalization strategy.

Wound-Healing Assay, IncuCyte Zoom, and Data Analysis. An IncuCyte Zoom live cell imaging microscope (Essen Bioscience, Welwyn Garden City, UK) with $10 \times$ objective and data management software was used to monitor cell migration in wound-healing assays. HaCaT cells were seeded overnight in $100 \mathrm{~mL}$ of growth medium at 15,000 cells/well in 96-well ImageLock plates (Essen Bioscience). Cells were washed twice in phosphate-buffered saline (PBS) and serum starved for 24 hours in DMEM supplemented with $0.2 \%$ FBS to minimize proliferation, which would interfere with migration assays. Uniform wounds were then generated using a WoundMaker (Essen Bioscience), and the cells were washed twice in PBS and then pretreated for 20 minutes with titrations of LY2157299 (galunisertib), SB-431542, AZ12601011, or AZ12799734 in DMEM/ $0.2 \% \mathrm{FBS}$. Cells were then treated with $\mathrm{BSA} / \mathrm{HCl}$ as a carrier control or TGF $\beta$ ( $5 \mathrm{ng} / \mathrm{mL})$. Closure of the wound was monitored by IncuCyte Zoom imaging over 4 days. Data presented are the mean \pm S.E.M. of a minimum of three replicate wells taken from a representative experiment. The mean \pm S.E.M. relative wound density was determined according to software processing definitions as recommended by the manufacturer.

In Vivo 4T1 Syngeneic Orthotopic Mammary Fat-Pad Model for Efficacy and Pharmacokinetics/Pharmacodynamics. The 4T1 cell line was maintained in RPMI 1640 (Invitrogen, Paisley, UK) supplemented with 10\% FCS (Sigma-Aldrich) and M1 (Egg Technologies, Wiltshire, UK) with glutamine (Invitrogen) in $7.5 \% \mathrm{CO}_{2}$ at $37^{\circ} \mathrm{C}$ and was detached using $0.05 \%$ trypsin (Invitrogen). Cells were implanted into mammary fat pad 4 in $30 \mu \mathrm{L}$ of PBS at $1 \times 10^{4}$ per mouse. Female BALB/c mice (Charles River, Harlow, UK) weighing more than $18 \mathrm{~g}$ had tumor sizes monitored three times weekly by bilateral caliper measurements. Tumor volume was calculated at each measure with dosing from the day following implant (Shaw et al., 2017). Controls received vehicle only (0.5\% Methocel E4 Premium, [Dow Chemical Company, USA]/0.1\% Polysorbate 80, [Sigma Aldrich, UK]) by oral gavage twice daily for the duration of the study. The treatment group received $50 \mathrm{mg} / \mathrm{kg} \mathrm{AZ12601011} \mathrm{twice} \mathrm{daily} \mathrm{in} \mathrm{0.5 \%}$ Methocel/0.1\% Polysorbate. Samples for pharmacokinetic and pharmacodynamic analysis were sampled at 1 and 6 hours post final morning dose on day 25. Additionally, lung samples were taken to assess the number of lung metastases. Each lobe was sectioned following formalin fixation, creating five serial sections per lobe, $200 \mu \mathrm{m}$ apart. The sections were then stained with hematoxylin and eosin stain, and the number of metastases were counted using light microscopy. This study was run in the UK in accordance with UK Home Office legislation, the Animal Scientific Procedures Act 1986, and AstraZeneca Global Bioethics policy. Experimental details are outlined in Home Office Project License 40/2934. Additional dosing was undertaken for PK profile analysis for AZ12601011 and AZ12799734 at $50 \mathrm{mg} / \mathrm{kg}$ per oral dose in male nude mice in vehicle as detailed earlier. Statistical analysis was carried out using SPSS software (IBM, Armonk, NY).

In Vivo Pharmacokinetic Analysis. Each plasma sample (25 $\mu \mathrm{L})$ was prepared using an appropriate dilution factor and compared against an 11-point standard calibration curve (1-10,000 $\mathrm{nM})$ prepared in DMSO and spiked into blank plasma. Acetonitrile $(100 \mu \mathrm{L})$ was added with the internal standard, followed by centrifugation at $3000 \mathrm{rpm}$ for 10 minutes. Supernatant $(50 \mu \mathrm{L})$ was then diluted in $300 \mu \mathrm{L}$ of water and analyzed via ultrahigh-performance liquid chromatography-tandem mass spectrometry. The mass spectrometer and ultrahigh-performance liquid chromatography parameters are detailed in Table 1, and the optimization parameters are presented in Table 2.

In Vivo Pharmacodynamic Analysis of Phospho-SMAD2 Using Enzyme-Linked Immunosorbent Assay. Mouse total SMAD 2/3 monoclonal antibody (catalog number 6108431; BD Biosciences, San Jose, CA) at $1.25 \mu \mathrm{g} / \mathrm{mL}$ in PBS was used to coat Greiner black high-bind 96-well plates with incubation for 1 hour at room temperature then inverted and blotted. Blocking buffer with $3 \%$ BSA (A-3912; Sigma-Aldrich) was added, and the incubation/blotting process was repeated. $4 \mathrm{~T} 1$ tumor lysate was prepared at $100 \mu \mathrm{g} / \mathrm{well}$ in AP lysis buffer containing fresh protease/phosphatase inhibitors and then added to the wells for an overnight incubation at $4^{\circ} \mathrm{C}$. Following this incubation, all wells were washed with Tris-buffered saline/ Tween 20. A plate was incubated with primary antibody (Rabbit Upstate phospho-SMAD2, 05-953), and a second plate was incubated with primary antibody (Rabbit CST Total SMAD 2/3, 3102; CST). Blocking buffer was used for the antibodies, and the plates were incubated for 2 hours at room temperature followed by washing with Tris-buffered saline/Tween 20. Anti-rabbit horseradish peroxidase conjugate (7074; CST) was added to the plates and incubated for 1 hour, followed by a further wash. The plates were developed with QuantaBlu (Thermo Fisher Scientific, Loughborough, UK) using the manufacturer's recommended protocol and read on a Tecan SpectroFluor (Tecan, Switzerland) using excitation at 340/465-nm emission.

TABLE 2

Optimization parameters for mass spectrometry analysis

\begin{tabular}{lcccccc}
\hline \multicolumn{1}{c}{ Compound } & Ionization Mode & Polarity & Parent Ion & Daughter Ion & Cone Voltage & Collison Energy \\
\hline & & & & & & $V$ \\
AZ12601011 & ESI & Positive & 314.2076 & 78.0667 & 80 & 46 \\
AZ12799734 & ESI & Positive & 371.15 & 290.21 & 50 & 34 \\
AZ10024306 (ISTD) & ESI & Positive & 408.253 & 174.189 & 80 & 22 \\
\hline
\end{tabular}

AZ10024306, 2-ethyl-4-\{[2'-(1H-tetrazol-5-yl)-4-biphenylyl]methoxy\}quinoline; ESI, Electrospray Ionisation; ISTD, Internal Standard. 
A<smiles>c1ccc(-c2nc3c(c(-n4ccc5cnccc54)n2)CCC3)nc1</smiles>

AZ12601011
AZ12799734<smiles>Cc1ccc(Oc2ccnc(Nc3ccc(S(N)(=O)=O)cc3)c2)c(C)n1</smiles>

B

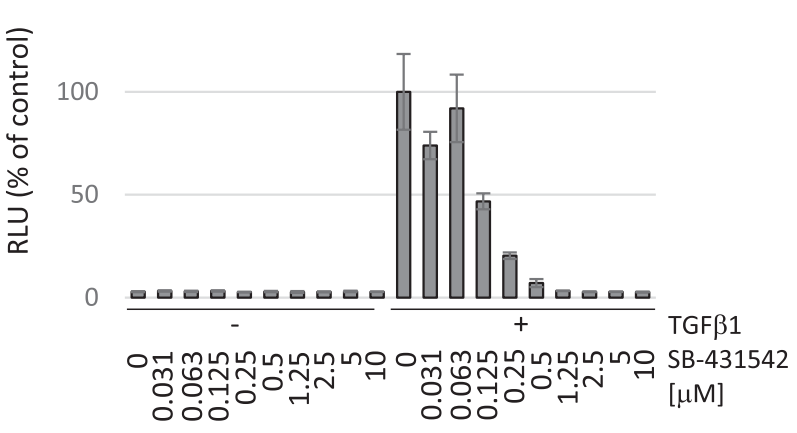

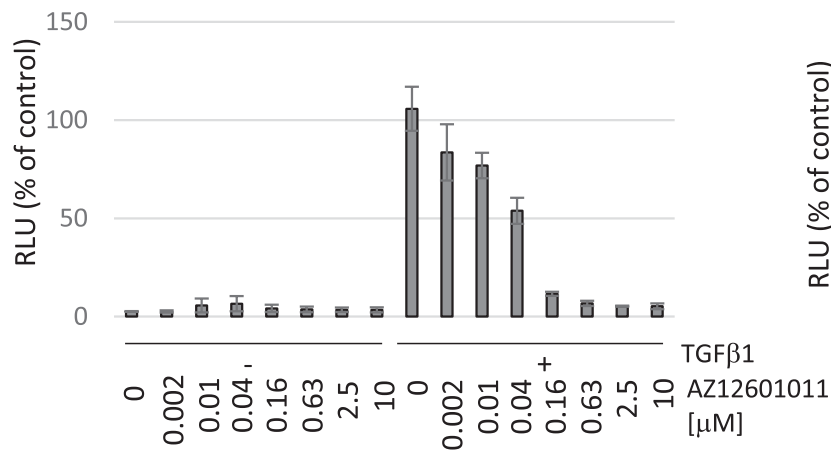
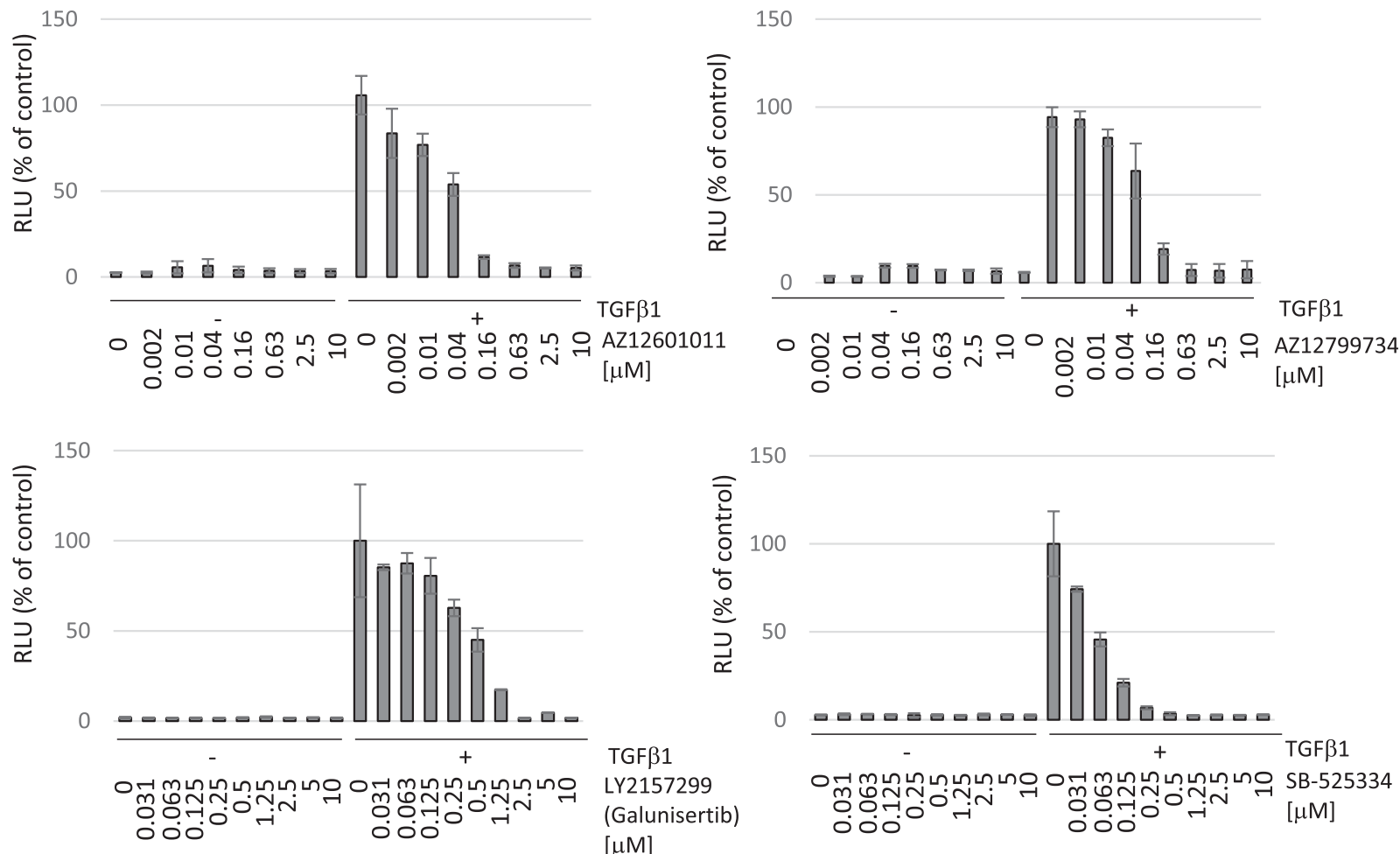

TGF $\beta 1$

LY2157299

(Galunisertib) [ $\mu \mathrm{M}]$

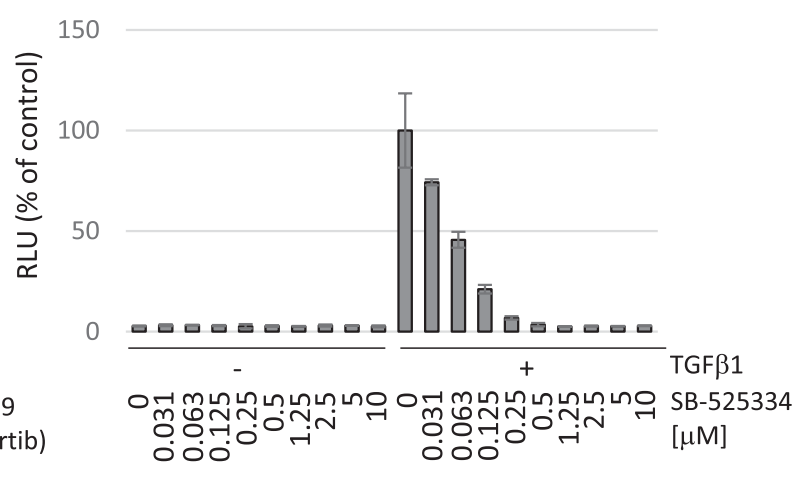

C

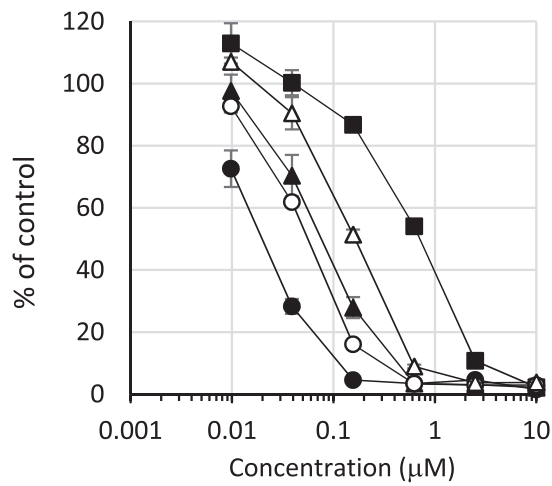

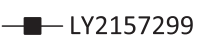

$\triangle$ ¿SB525334

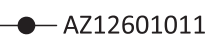

-O-AZ12799734

$\triangle$ SB-431542
D

\begin{tabular}{|c|c|c|c|}
\cline { 2 - 4 } \multicolumn{1}{c|}{} & $\begin{array}{c}\text { Median effect } \\
\text { plots }\end{array}$ & \multicolumn{2}{c|}{$\begin{array}{c}\text { Non-linear regression } \\
\text { curve fit }\end{array}$} \\
\cline { 2 - 4 } & $\mathrm{IC}_{50}(\mu \mathrm{M}) \pm \mathrm{s} . \mathrm{d}$ & $\mathrm{IC}_{50}(\mu \mathrm{M})$ & $95 \% \mathrm{Cl}$ \\
\hline AZ12601011 & $0.018 \pm 0.006$ & 0.019 & 0.014 to 0.026 \\
\hline AZ12799734 & $0.047 \pm 0.007$ & 0.052 & 0.044 to 0.061 \\
\hline SB-525334 & $0.074 \pm 0.027$ & 0.059 & 0.036 to 0.093 \\
\hline SB-431542 & $0.084 \pm 0.031$ & 0.145 & 0.122 to 0.169 \\
\hline LY2157299 & $0.38 \pm 0.17$ & 0.558 & 0.429 to 0.736 \\
\hline
\end{tabular}

Fig. 1. Activity of five TGFBR1 inhibitors in TGF $\beta$-induced SMAD3/4-dependent reporter assays. (A) Chemical structures of AZ12601011 (previously undisclosed) and AZ12799734 (Goldberg et al., 2009). (B) TGF $\beta$-inducible SMAD3/4-dependent CAGA12 promoter-luciferase reporter bioassay carried out in both the absence $(-)$ and presence $(+)$ of exogenous addition of TGF $\beta 1(1 \mathrm{ng} / \mathrm{mL})$ for 8 hours. Stably transfected NIH3T3 CAGA12 cells were pretreated with a titration of SB-431542, SB-525334, AZ12601011, AZ12799734, or LY2157299 for 15 minutes prior to induction of luciferase activity by exogenous TGF $\beta$ addition. The mean ( \pm S.D.) activity (as a percentage of the control cells + TGF $\beta$ ) is shown from a representative experiment. (C) Representative dose-response curves of TGFBR1 inhibitors generated from CAGA12 bioassays as shown in (B). Data are presented as a percentage of luciferase activity of untreated control cells + TGF $\beta$ (100\%). (D) Mean \pm S.D. IC $_{50}$ determined by median effect plots using CalcuSyn curve fit software and $\mathrm{IC}_{50}$ and $95 \%$ confidence intervals $(95 \%$ CIs) determined by nonlinear regression analysis using GraphPad Prism 7 software are shown. The IC 50 values were generated from replicate independent dose-response curves [AZ12601011 $(n=4), \operatorname{AZ12799734}(n=3)$, SB-525334 $(n=4)$, SB-431542 $(n=5)$, LY2157299 $(n=4)]$. RLU, relative luciferase units. 
A

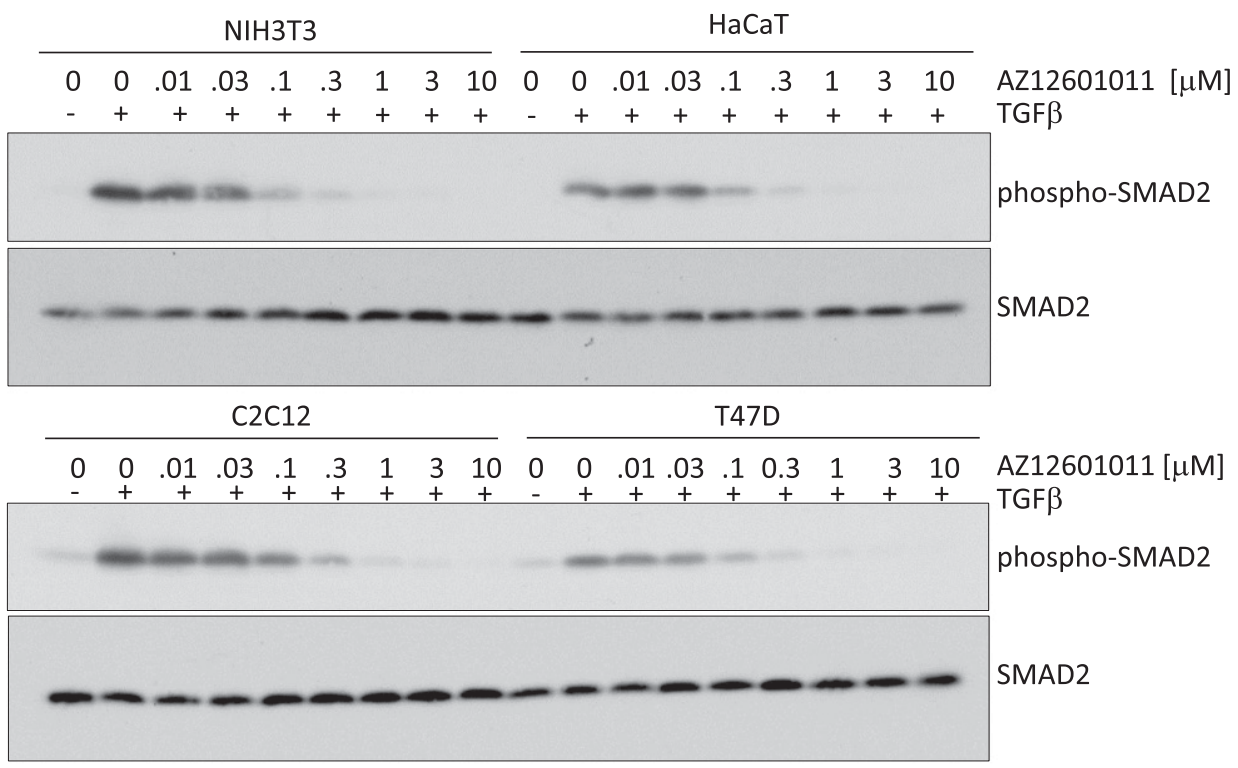

B

C

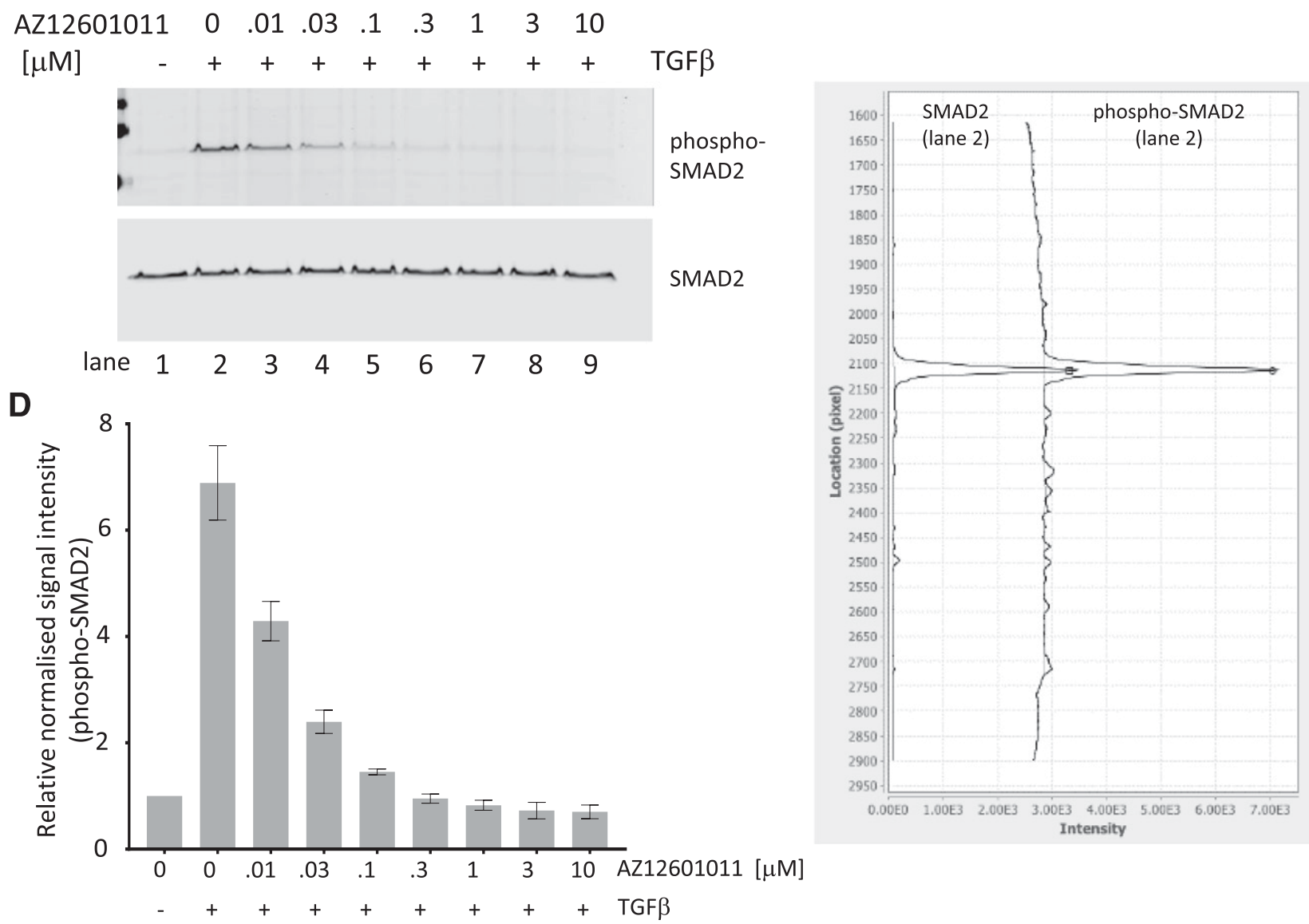

Fig. 2. Inhibition of TGF $\beta$-induced phosphorylation of SMAD2 by AZ12601011. (A) Representative SDS-PAGE and western blot analysis for phosphorylated SMAD2 and total SMAD2 of radioimmunoprecipitation assay buffer (RIPA) lysates from two independent experiments where cell lines were pretreated with a titration of AZ12601011 for 20 minutes followed by exogenous addition of TGF $\beta$ ( 5 ng/mL) for 1 hour. (B-D) LI-COR Odyssey infrared imaging quantification of phospho-SMAD2 (ser465/467) normalized to pan-SMAD2 levels in HaCaT cells pretreated with a titration of AZ12601011 (range 10-0.01 $\mu \mathrm{M})$ prior to TGF $\beta$ addition for 1 hour $(n=3)$. Representative scanned blots (B) and combined raw intensity signals from infrared imaging of pan-SMAD2 and phospho-SMAD2 western blots, lane 2 (untreated + TGF $\beta$ ) (C). (D) Bar chart depicting the mean \pm S.E.M. $(n=3)$ ratio of phospho-SMAD2 normalized signal intensity relative to the untreated control (lane 1) from replicate assays. 


\section{Results}

AZ12601011 and AZ12799734 Inhibit Ligand-Activated SMAD3/4 Transcription. NIH3T3 cells stably expressing a TGF $\beta$-inducible CAGA12-luciferase reporter construct were used to determine the effect of AZ12601011 and AZ12799734 (compound structures are shown in Fig. 1A) on TGF $\beta$ induced transcription in comparison with the previously characterized TGFBR1 inhibitors SB-431542, SB-525334, and LY2157299 (galunisertib). The 12 tandem copies of the SMAD binding element CAGA (Dennler et al., 1998) regulate luciferase reporter gene activity in response to TGF $\beta$ receptor-regulated SMAD3 and SMAD4 binding. Luciferase activity in cell lysates increased in response to $\operatorname{TGF} \beta 1$ addition and was inhibited by all compounds tested (Fig. $1 B)$. The $\mathrm{IC}_{50}$ values, determined by curve fitting from doseresponse curves (Fig. 1C) of AZ12601011 (18 $\pm 6 \mathrm{nM})$ and AZ12799734 (47 $\pm 7 \mathrm{nM})$, were lower than those of the other inhibitors and were approximately 10 -fold lower than the $\mathrm{IC}_{50}$ of galunisertib (384 $\pm 170 \mathrm{nM}$ ), approved for use in clinical trials (Fig. 1, C and D). Phosphorylation of SMAD2 induced by exogenous TGF $\beta$ addition, detected using a polyclonal rabbit antiphosphorylated SMAD2 (ser465/467) antibody, was completely inhibited by the most active inhibitor, AZ12601011, in four cell lines at concentrations between $300 \mathrm{nM}$ and $1 \mu \mathrm{M}$ (Fig. $2 \mathrm{~A})$. The inhibition of SMAD2 phosphorylation in TGF $\beta$-treated $\mathrm{HaCaT}$ relative to pan-SMAD2 levels was quantified by LI-COR infrared imaging using a second monoclonal rabbit antiphosphorylated SMAD2 (ser465/467) (138D4) antibody (Fig. 2, B-D). Representative blots are shown in Fig. 2B, and combined raw intensity traces from channel 700 and 800 scans of lane 2 (control + $\mathrm{TGF} \beta$ ) measuring phospho-SMAD2 and pan-SMAD2, respectively, are shown in Fig. 2C. Normalized phospho-SMAD2 levels relative to uninduced levels (lane 1) are shown in Fig. 2D; these returned to baseline in the presence of $0.3 \mu \mathrm{M} \mathrm{AZ12601011} \mathrm{and}$ indicate levels of inhibition similar to those seen in Fig. 2A.
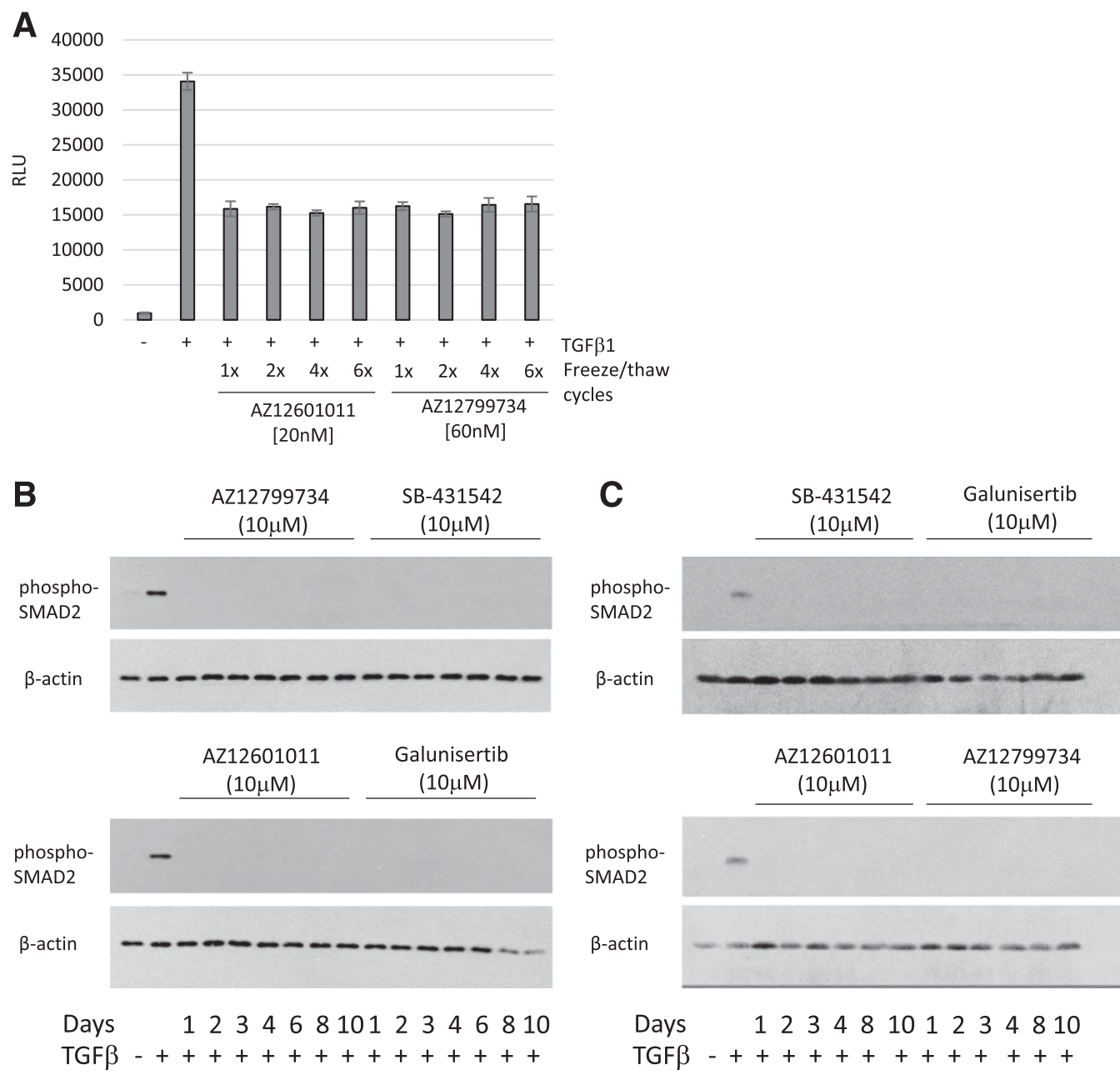

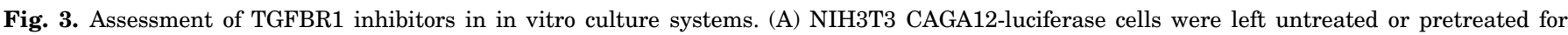

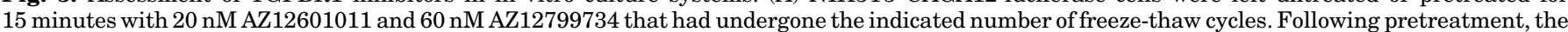

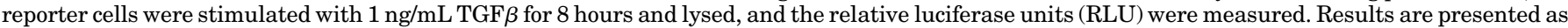

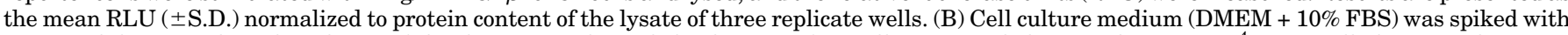

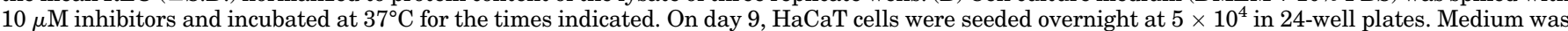

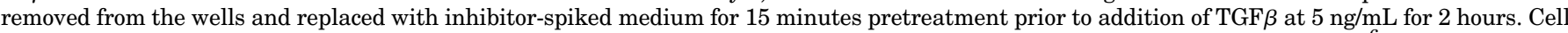

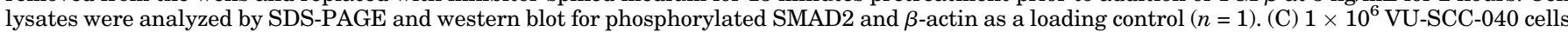

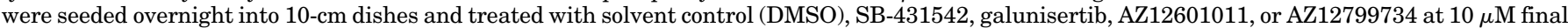

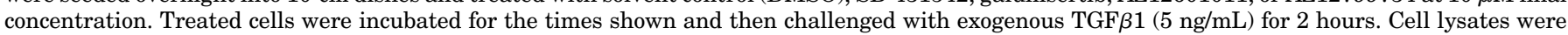

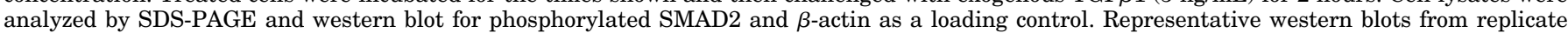
biologic experiments $(n=2)$ showing similar results are shown. 


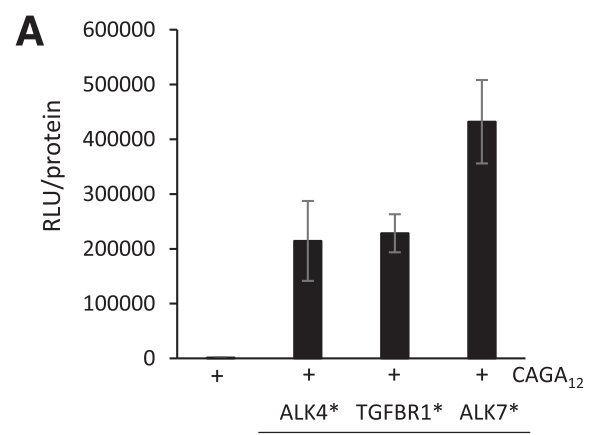

B
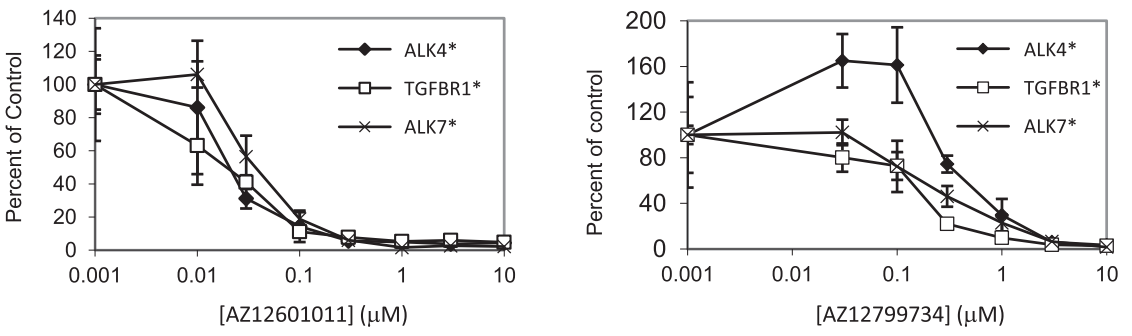

C

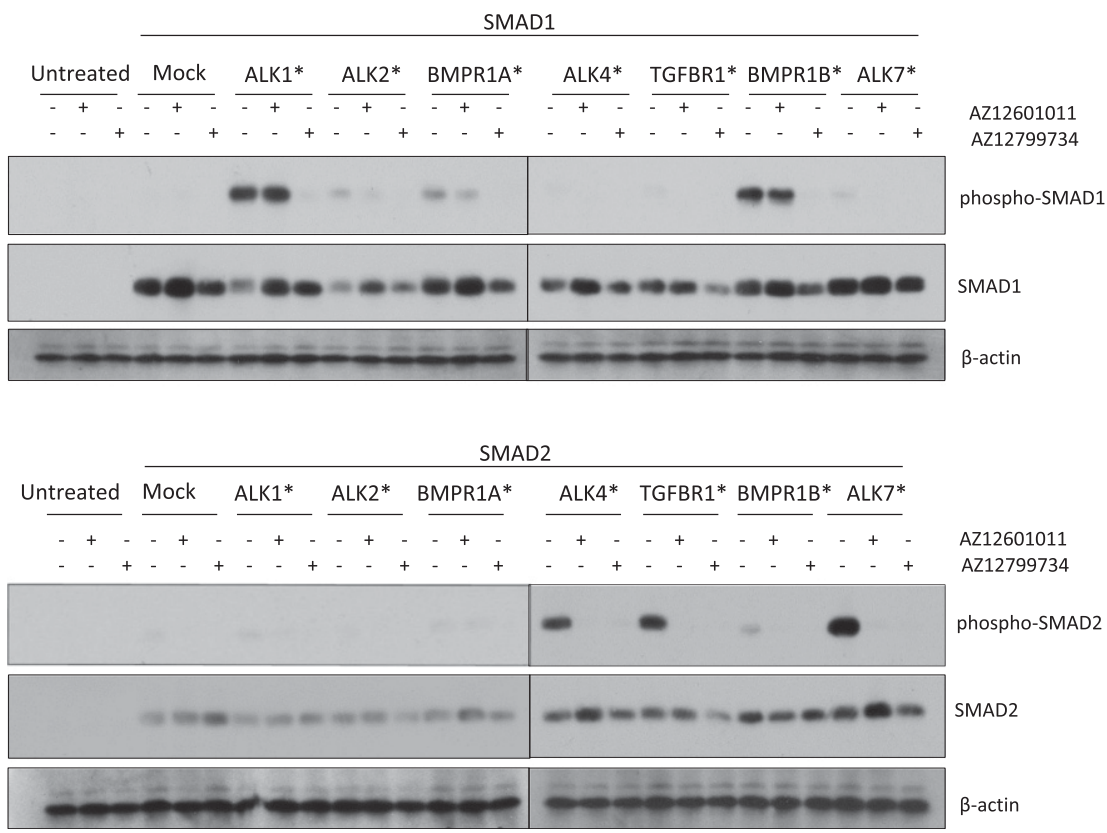

Fig. 4. Selectivity of AZ12601011 and AZ12799734 against TGF $\beta$ superfamily type 1 receptors. (A and $\mathrm{B}) 4.5 \times 10^{4} \mathrm{NIH} 3 \mathrm{~T} 3$ cells were seeded in 24 -well plates and incubated overnight. Cells were transfected with $100 \mathrm{ng}$ of CAGA12-luciferase reporter and $150 \mathrm{ng}$ of plasmids expressing constitutively active (*) type 1 receptors ALK4, TGFBR1, or ALK7. After 24 hours, the relative luciferase activity was measured in cell lysates. Relative luciferase units (RLUs) were normalized to protein content and expressed as the mean RLU ( \pm S.D.) from a minimum of three replicate wells. (B) Cells were transfected as described in (A) and treated with a titration of either AZ12601011 or AZ12799734 as indicated. Results are shown as the mean percentage RLU ( \pm S.D.) relative to control samples. (C) NIH3T3 cells were cotransfected in singlicate with $500 \mathrm{ng}$ of SMAD1 or SMAD2 expression plasmids and $500 \mathrm{ng}$ of plasmids expressing constitutively active ${ }^{*}$ ) receptors. Cells were either left untreated or treated with $10 \mu \mathrm{M}$ AZ12601011 or AZ12799734 for 24 hours prior to lysis and analysis of lysates by SDS-PAGE and western blotting for the proteins indicated. Black vertical lines indicate separate gels that were run and blotted concurrently.
Stability and Specificity of AZ12601011 and AZ12799734. We next tested the suitability, stability, and specificity of AZ12601011 and AZ12799734 as reagents for studying TGF $\beta$ family signaling in cell-based assays. Neither AZ12601011 nor AZ12799734 showed any reduction in their ability to block CAGA12-luciferase reporter activity following up to six rounds of freeze-thawing when used at concentrations selected to inhibit CAGA12 activity by approximately 50\% (20 and $60 \mathrm{nM}$, respectively) (Fig. 3A). All four inhibitors tested maintained activity when incubated in tissue culture medium for up to 10 days (Fig. 3B) and effectively maintained efficacy in in vitro cell culture assays over this time period as assessed by the ability to block TGF $\beta$-mediated induction of SMAD2 phosphorylation (Fig. 3C). AZ12601011 and AZ12799734 can therefore be used to effectively block TGF $\beta$ signaling in phenotypic assays over a 10-day time course.

Previous drugs designed to target the TGF $\beta$ type 1 receptor, such as SB-431542, effectively inhibit the activity of activin and nodal receptors ALK4 and ALK7 in addition to TGFBR1. Therefore, using transient transfection assays, we also assessed the effect of AZ12601011 and AZ12799734 on constitutively active ALK4, ALK7, and TGFBR1 receptors expressed in NIH3T3 CAGA12 reporter cells. Induction of CAGA12-luciferase reporter activity induced by transient transfection of the constitutively active receptors is shown in Fig. 4A. Following transient transfection, cells were treated with a titration of AZ12601011 and AZ12799734, and the effect on CAGA12 reporter activity was monitored (Fig. 4B). AZ12601011 inhibited the activity of ALK4, ALK7, and TGFBR1 equally at concentrations 

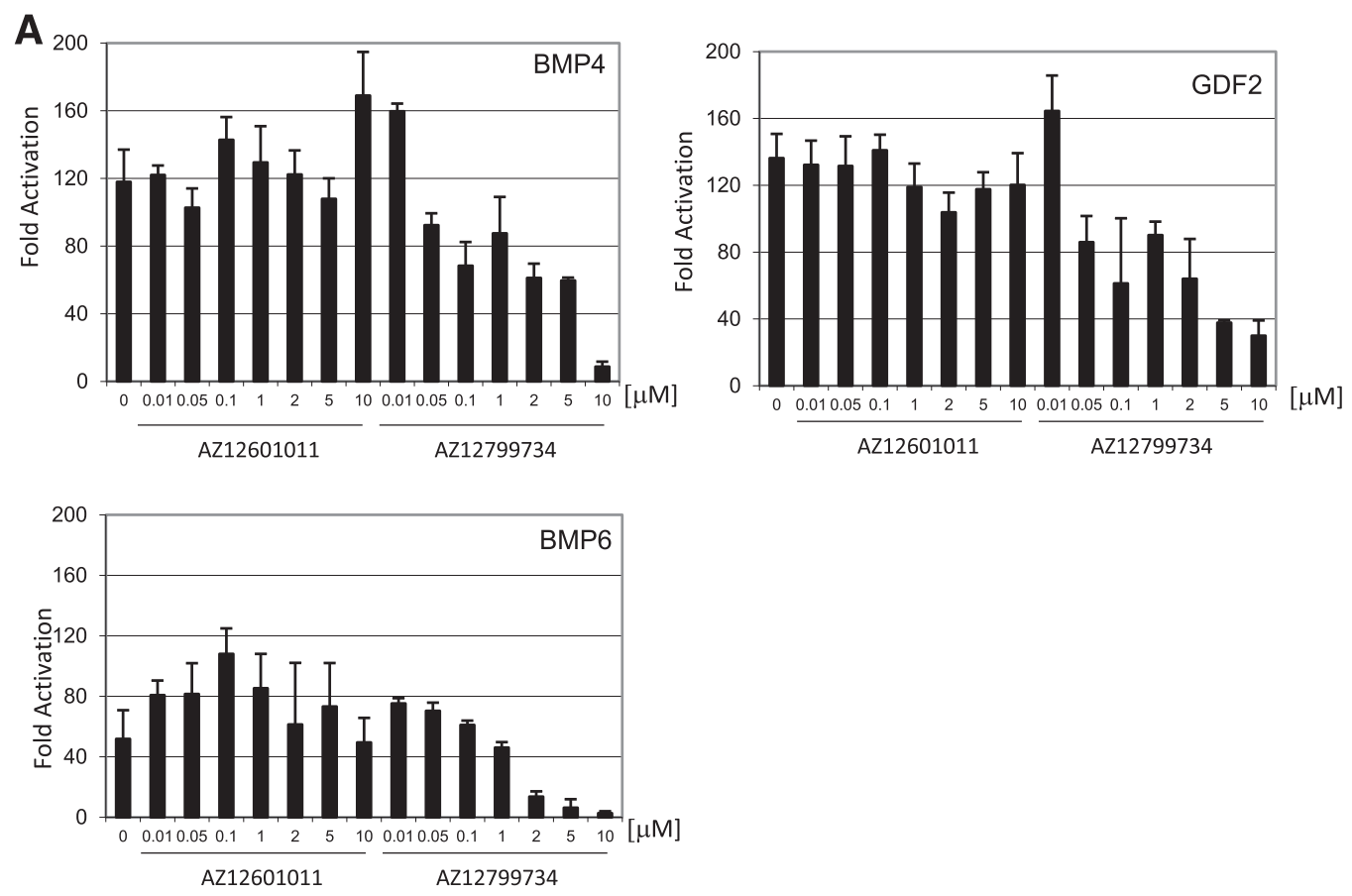

B
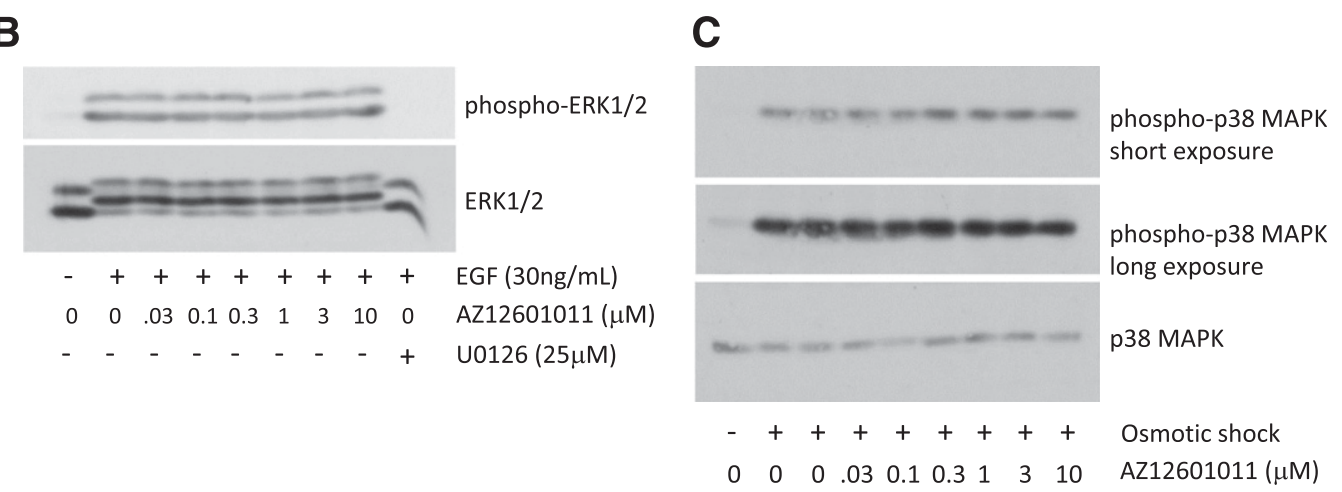

Fig. 5. Selectivity of AZ12601011 and AZ12799734 in cell-based assays. (A) C2C12-BRE-LUC cells were pretreated with a titration of AZ12601011 and AZ12799734 for 20 minutes prior to addition of $5 \mathrm{ng} / \mathrm{mL}$ recombinant BMP ligand. Luciferase activity was measured using the Luciferase Assay system (Promega). Results presented are the mean fold activation of the luciferase reporter in response to ligand relative to activity in untreated cells. (B and C) Serum-starved (0.1\% FBS) NIH3T3 cells were pretreated in singlicate with a titration of AZ12601011 (as indicated) for 20 minutes prior to stimulation for 5 minutes with EGF (30 ng/mL) (B) or osmotic shock treatment for 20 minutes with $\mathrm{NaCl}(0.7 \mathrm{M})(\mathrm{C})$. (B) U0126 treatment at $25 \mu \mathrm{M}$ was included as a positive control for inhibition of EGF signaling via the MAPK pathway. Cells were then washed in ice-cold PBS and lysed in radioimmunoprecipitation assay buffer (RIPA). Protein lysates were quantified, and equal amounts of protein were analyzed by SDS-PAGE; western blots for the proteins indicated are shown. GDF2, growth differentiation factor 2.

between 0.01 and $10 \mu \mathrm{M}$. AZ12799734 also equally inhibited the three constitutively active receptors at concentrations ranging from 1 to $10 \mu \mathrm{M}$. We next tested the effect of AZ12601011 and AZ12799734 on receptor-regulated SMAD phosphorylation by transient transfection of constitutively active receptors into NIH3T3 cells (Fig. 4C). Phosphorylation of cotransfected SMAD1 and SMAD2 by the active receptors was monitored by western blot. All seven receptors induced phosphorylation of either SMAD1 or SMAD2; as expected, phosphorylation of SMAD1 occurred following transfection of ALK1, BMPR1A, and BMPR1B, and phosphorylation of SMAD2 occurred following transfection of ALK4, TGFBR1, and ALK7 (Fig. 4C). AZ12601011 inhibited phosphorylation of SMAD2 but not SMAD1, suggesting that (similar to SB-431542) AZ12601011 is a selective inhibitor of ALK4, TGFBR1, and ALK7.
AZ12799734, however, inhibited phosphorylation of both SMAD1 and SMAD2 and is thus likely to be a pan BMP/TGF receptor inhibitor. The effect of AZ12799734 on BMP signaling was confirmed using a bioassay measuring the transcriptional activation of a BMP responsive element luciferase reporter construct (C2C12-BRE-LUC) (Herrera and Inman, 2009) after exogenous addition of BMP4, BMP6, or growth differentiation factor 2 (BMP9). As expected, given that there was no effect of AZ12601011 on SMAD1 phosphorylation, we saw no inhibition of BMP-induced activity of C2C12-BRE-LUC in AZ12601011-treated cells (Fig. 5A). Following treatment by AZ12601011, we observed no inhibition of extracellular signals regulating phosphorylation of ERK (induced by EGF) (Fig. 5B) or p38 MAPK family members (induced by osmotic shock) (Fig. 5C). Therefore, AZ12601011 had no inhibitory offtarget effect on the EGF-activated epidermal growth factor 

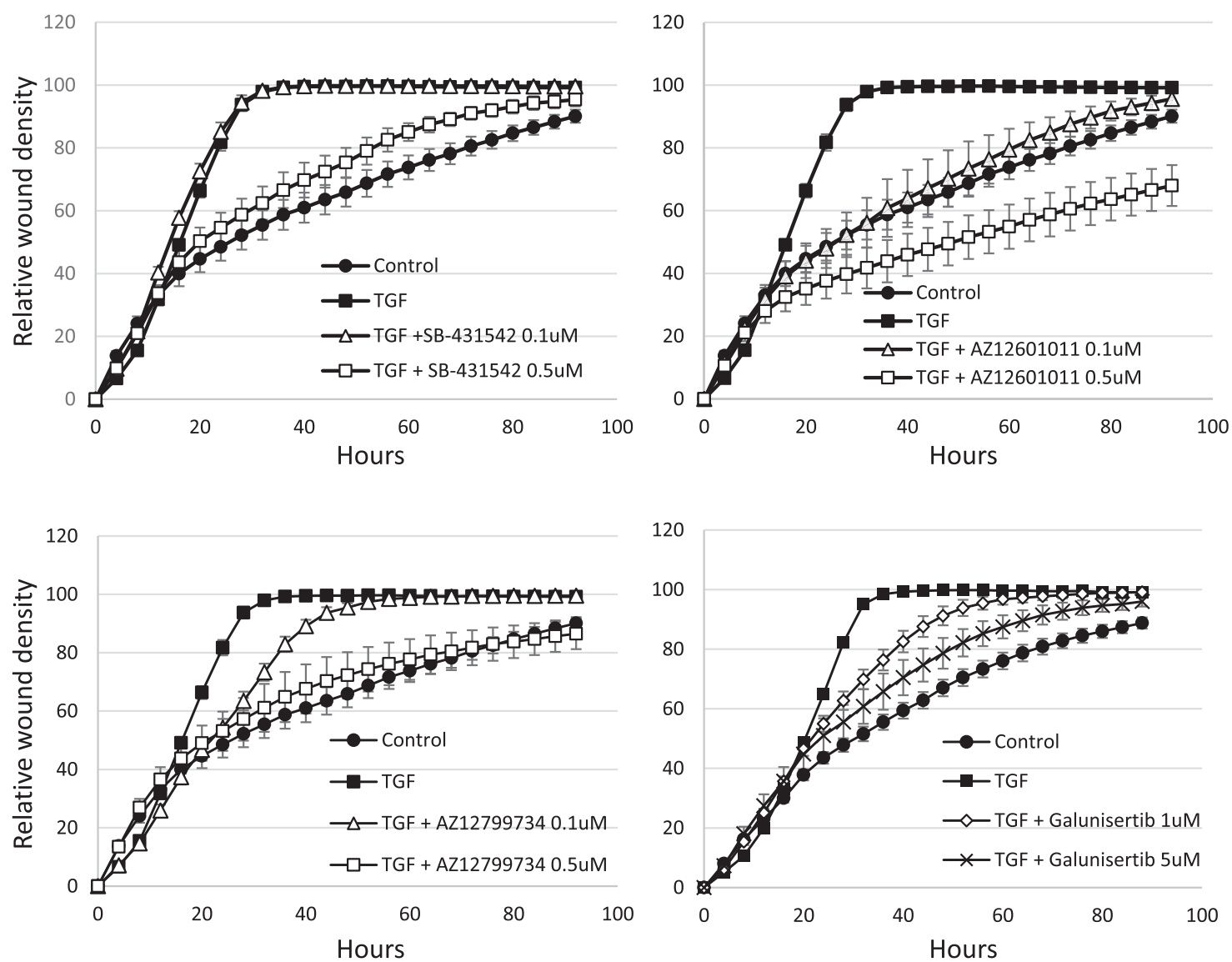

Fig. 6. Blockade of TGF $\beta$-induced migration. HaCaT cells were seeded at 15,000 cells/well in ImageLock plates (Essen Biosciences) and incubated overnight. Cells were washed twice in PBS and serum starved for 24 hours in DMEM supplemented with $0.2 \%$ FBS. Uniform wounds were generated using a WoundMaker, and the cells were washed twice in PBS and then pretreated with titrations of SB-431542, AZ12601011, or AZ12799734 in DMEM/ $0.2 \%$ FBS followed by BSA/HCl carrier control or TGF $\beta(5 \mathrm{ng} / \mathrm{mL})$. Closure of the wound was monitored by IncuCyte Zoom imaging over 4 days. Data presented are the mean \pm S.E.M. of a minimum of three replicate wells taken from a representative experiment.

receptor/MEK/ERK signaling cascade (Bogdan and Klämbt, 2001), which was efficiently blocked by the MEK1/2 inhibitor U0126, which was used as a positive control for MEK1/2 inhibition (Fig. 5B).

AZ12601011 and AZ12799734 Inhibit TGF $\beta$-Induced Migration. AZ12601011 and AZ12799734 were assessed in functional wound-healing assays using $\mathrm{HaCaT}$ epithelial cells that measure TGF $\beta$-inducible SMAD4-dependent migration responses (Levy and Hill, 2005). Confluent monolayers of serum-starved $(0.2 \% \mathrm{FBS}) \mathrm{HaCaT}$ cells were uniformly scratched using a WoundMaker (Essen Biosciences), and the resulting wound closure was analyzed by real-time imaging (Fig. 6). Serum-starved DMSO control-treated cells migrated to close the wound by just over $80 \%$ after 80 hours of incubation. Following treatment with $\operatorname{TGF} \beta$, however, $\mathrm{HaCaT}$ cells migrated faster to close the wound entirely within 36 hours. When cells were pretreated with different concentrations of SB-431542, galunisertib, AZ12601011, or AZ12799734 prior to TGF $\beta$ addition, we observed dose-dependent decreases in TGF $\beta$-induced migration. SB-431542, galunisertib, AZ12601011, and AZ12799734 blocked the increase in migration at concentrations of $500,5000,100$, and $500 \mathrm{nM}$, respectively. At $500 \mathrm{nM}, \mathrm{AZ} 12601011$ reduced cell migration below baseline, which was only achieved at doses of $\geq 5 \mu \mathrm{M}$ SB431542 and AZ12799734 (data not shown). AZ12601011, therefore, was the most effective inhibitor in the wound-healing assay, inhibiting TGF $\beta$-induced migration at concentrations at least 10-fold lower than galunisertib.

AZ12601011 Inhibits Tumor Growth and Metastasis In Vivo. The selectivity profile of AZ12601011 for ALK4, TGFBR1, and ALK7 (similar in scope to galunisertib in clinical trials) made it a good representative probe molecule to understand the profile of a TGFBR1 inhibitor in vivo. We tested the pharmacokinetics of both drugs (total and free) in BALB/c mice following administration of a $50-\mathrm{mg} / \mathrm{kg}$ dose (Fig. 7A) and tested the effect of AZ12601011 on 4T1 cell proliferation in vitro prior to its use in an in vivo assay of preventative treatment of 4T1 syngeneic orthotopic tumor growth. AZ12601011 inhibited 4T1 proliferation with an $\mathrm{IC}_{50}$ of $400 \mathrm{nM}$ (Fig. 7B). In the orthotopic in vivo assay, AZ12601011 inhibited signaling measured by a reduction in phosphorylated SMAD2 detected in tumor cell lysates 1 hour after administration (50 mg/kg) (Fig. 7C). AZ12601011 inhibited 4T1 cell growth in vitro $\left(\mathrm{IC}_{50}=0.4 \mu \mathrm{M}\right)$ (Fig. 7C). To assess efficacy in vivo, mice were treated twice daily with vehicle or AZ12601011 (50 mg/kg) starting the day after implantation of $4 \mathrm{~T} 1$ cells into mammary fat pads. Tumor growth was monitored over 25 days (Fig. 7D). The average tumor size in the treated group $(n=10)$ up to day 18 (when $13 / 13$ mice in the control group remained in the study) was significantly inhibited by AZ12601011 $(P=0.0001)$ compared with controls $(n=13)$ (Fig. 7E). Two of 13 mice in the control 

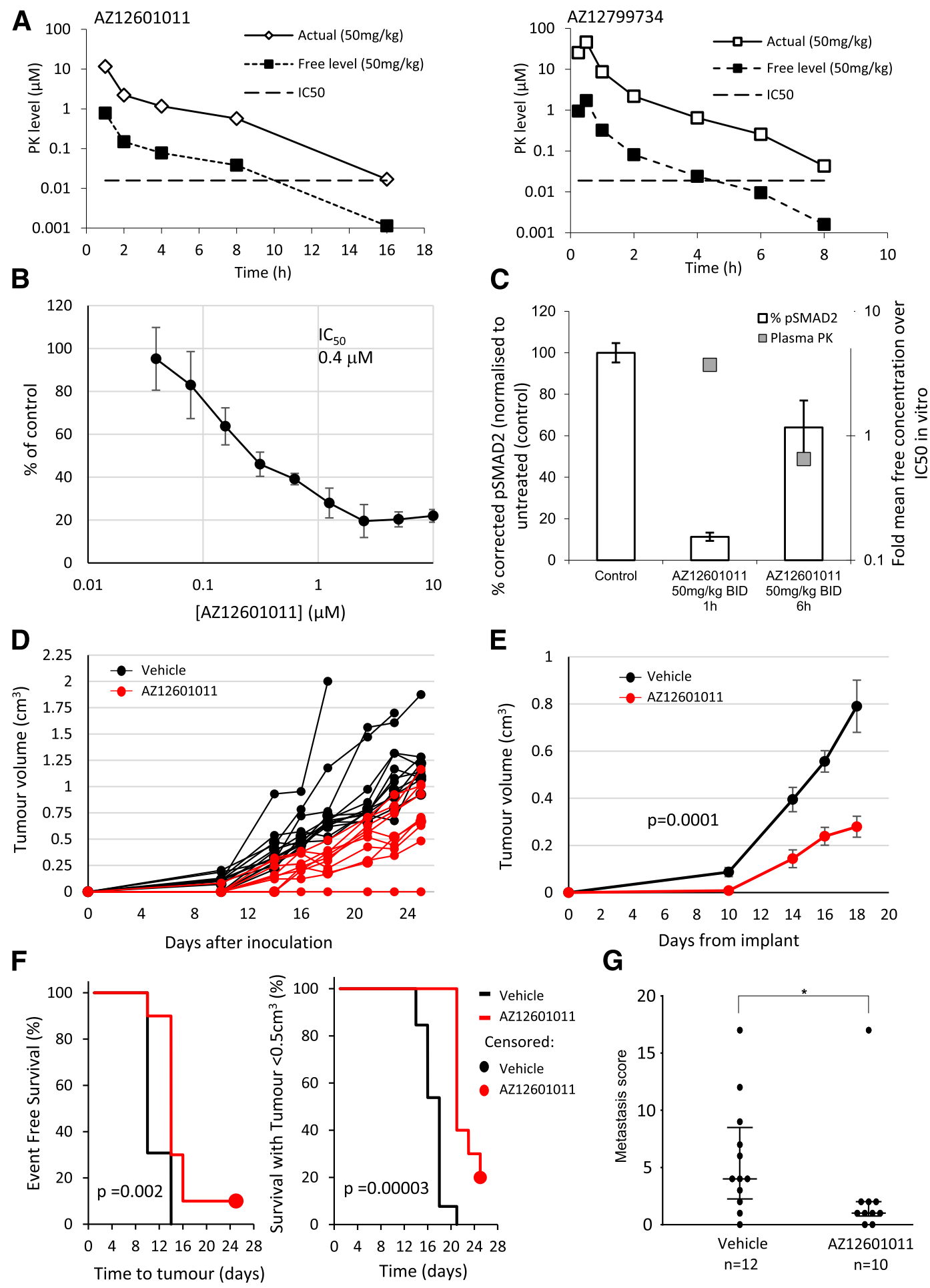

Fig. 7. In vivo profile of TGFBR1 inhibitors. (A) Total and free pharmacokinetic (PK) levels of AZ12601011 and AZ12799734 in the nude mouse following $50 \mathrm{mg} / \mathrm{kg}$ per oral dose, with time over in vitro $\mathrm{IC}_{50}(0.01582$ and $0.01885 \mu \mathrm{M}$, respectively). (B) Growth of $4 \mathrm{~T} 1$ cells (shown as a percentage of vehicle-treated control cells) treated with AZ12601011. Growth was determined after 4 days of treatment using the IncucyteZoom real-time imaging system. (C) Pharmacodynamic modulation of phosphorylated SMAD2 (pSMAD2) levels following treatment of with AZ12601011 [50 mg/kg twice daily (BID)] in the mouse 4T1 syngeneic cell line grown via mammary orthotopic implant. pSMAD2 levels were measured in tumor cell lysates by enzyme-linked immunosorbent assay 1 hour after drug administration. (D) Mouse 4T1 syngeneic orthotopic tumor growth over 25 days in vehicle control $(n=13)$ and AZ12601011-treated (50 mg/kg BID; $n=10)$ mice. Mice were treated by oral gavage twice daily from day 1 following implant. Tumor volumes in individual mice are shown. (E) Mean \pm S.E.M. tumor volumes of all mice in the vehicle control and AZ12601011-treated groups until day of first sacrifice (day 18). Statistical analysis was carried out by pairwise comparison using the compareGrowthCurves function in statmod (R Project). The adjusted $P$ value is shown. (F) Kaplan-Meier plots showing statistically significant differences in event-free (left) [log rank (Mantel-Cox) $\chi 2(1)=9.191, P<0.002]$ and tumor $<0.5 \mathrm{~cm}^{3}$ (right) [ $\log$ rank (Mantel-Cox) $\chi 2(1)=17.448, P=0.00003$ ] survival (control group, $n=13$; treated group, $n=10$ ). (G) Scatterplot showing relative lung metastasis scores in the 4T1 syngeneic orthotopic tumor mice [described in (D)-(F)] following vehicle control $(n=12)$ or AZ12601011 treatment $(n=10)$. The scatterplot points represent individual mice, and bars represent the median and interquartile ranges. Analysis was carried out using Mann-Whitney $U$ test. AZ12601011-treated group: median = 1; vehicle control group: median $=4, \mathrm{U}=26, \mathrm{z}=-2.267, P=0.025$, using an exact sampling distribution for $\mathrm{U}$. 
group had to be sacrificed before the end of the study at days 18 and 23 due to large tumor sizes. No tumors in the treated group exceeded the stipulated size limit, and one of 10 mice did not develop a measurable tumor. We noted a significant increase in event-free survival $(P=0.002)$ and in the time taken to develop tumors exceeding $0.5 \mathrm{~cm}^{3}(P<0.005)$ in the treated mice (Fig. 7F). Importantly, we also found a statistically significant reduction $(P=0.025)$ in the median lung metastasis score in mice treated with AZ12601011 (median = 1) compared with the control group (median $=4 ; \mathrm{U}=26$, $\mathrm{z}=-2.267$, using an exact sampling distribution for $\mathrm{U}$ ).

Therefore, AZ12601011 shows efficacy as a single-agent therapy in tumor model systems providing a TGFBR1 inhibitor lead compound for future development.

\section{Discussion}

Our data describe the specificity and efficacy of two compounds designed to inhibit TGFBR1 kinase activity (AZ12601011 and AZ12799734) in a number of cell-based assays. We provide evidence that AZ12601011 targets ALK4 and ALK7 as well as TGFBR1, whereas AZ12799734 is a pan inhibitor of ALK1, ALK2, BMPR1A, ALK4, TGFBR1, BMPR1B, and ALK7. Thus, although not directly tested here, we predict that similar to SB-431542, AZ12601011 will also inhibit activin and nodal signaling through ALK4 and ALK7. AZ12799734, we anticipate, may be useful as a single-agent combined inhibitor of TGF $\beta$ and BMP activity.

The efficacy of AZ12601011 and AZ12799734 was also assessed in biological assays of TGF $\beta$-induced transcription and migration. TGF $\beta$-induced migration of $\mathrm{HaCaT}$ epithelial cells is, in part, reported to involve TGF $\beta$-mediated activation of a genetic program regulated by the ERK signaling pathway demonstrated by the observation that the MEK/ERK inhibitor U0126 can inhibit this response (Zavadil et al., 2001). Since $100 \mathrm{nM}$ concentrations of AZ12601011 inhibited migration but had no effect on EGF-induced phosphorylation of ERK or p38 phosphorylation up to concentrations of $10 \mu \mathrm{M}$, we conclude that the effects of the inhibitors on migration are not a result of off-target inhibition of MEK/ERK but are likely a result of on-target TGFBR1 inhibition. In these assays, AZ12601011 and AZ12799734 were at least 10-fold more effective in blocking TGF $\beta$-induced transcription and migration than galunisertib, currently in clinical trials. Importantly, AZ12601011 reduced signaling via SMAD2 in vivo and inhibited tumor growth and metastasis in an orthotopic murine model of breast cancer, suggesting therapeutic potential.

The development of novel inhibitors of TGFBR1 could provide new therapeutic options in TGF $\beta$-associated pathologies, such as cancer and fibrosis. The clinical use of TGFBR1 inhibitors, however, is not without concerns over patient safety. TGF $\beta$ signaling via TGFBR1 has a role in cardiac development (Sridurongrit et al., 2008), and several heart defects are evident in TGF $\beta 2$-null mice. Because increased TGF $\beta$ expression is involved in cardiac remodeling in response to numerous stresses (Lim and Zhu, 2006), TGFBR1 inhibitors are predicted to be of benefit in combating the effects of cardiac remodeling in heart failure. However, administration of AZ12601011 to disease-free wild-type mice is associated with cardiac toxicity involving the development of aortic lesions (Anderton et al., 2011). Questions over these homeostatic functions of TGF $\beta$ have thus delayed development of lead compounds, such as LY2157299 (galunisertib). Similar effects of galunisertib on small mammals were noted during detailed preclinical toxicity testing but were ameliorated by lower doses and careful dosing schedules (Herbertz et al., 2015). These concerns therefore appear to be largely overcome, and several cancer-related trials of galunisertib as a monotherapy, or in combination with other chemotherapeutics, are ongoing. The efficacy of galunisertib in models of cancer, however, appears limited by tumor environmental factors, and antitumor growth inhibitory effects are lacking in some xenograft models (Herbertz et al., 2015; Maier et al., 2015). In hepatocellular cancer cells, galunisertib had minimal effects on proliferation but inhibited invasion (Serova et al., 2015). Most of the studies to date have focused on antiproliferative and tumor-killing potential in standard assays, and there is growing evidence that these inhibitors may be more effective in cancer models measuring metastasis, immune function, and cancer stem cell-like properties (Peñuelas et al., 2009; Anido et al., 2010; Maurantonio et al., 2011; Spender et al., 2016). For example, galunisertib has been shown to inhibit TGF $\beta$-induced migration and immune suppression in vitro (Yingling et al., 2017). In addition, SB-431542 inhibits mutant BRAF melanoma cell migration and stem cell-like properties of anchorage-independent growth and clonogenicity at lowcell density. These effects are overcome by increasing cell density, leading to the conclusion that the dependence of tumor cells on TGF $\beta / T G F B R 1$ signaling is revealed under conditions of cellular stress. Therefore, TGFBR1 inhibitors may be most effective in inhibiting micrometastasis seeding or outgrowth, following removal of any clinically apparent tumor mass (Spender et al., 2016). This conclusion is supported by the inhibitory effect of AZ12601011 on HaCaT cell migration and the formation of 4T1 lung metastasis in our experimental cell-based assays. Hence, $\mathrm{TGF} \beta$ receptor inhibitors remain candidate therapeutic agents with therapeutic potential, despite the lack of significant tumor killing by galunisertib. Additionally, galunisertib has shown promise in ex vivo models of fibrotic disease (Luangmonkong et al., 2017). Therefore, AZ12601011 and AZ12799734 provide new tools for studying TGF $\beta$ - and BMP-regulated biologic processes and lead compounds for clinical development.

\section{Acknowledgments}

We express gratitude to the following people who provided assistance: In vivo tissue culture support was provided by Suzanne Meredith. Drug Metabolism and pharmacokinetics (DMPK) method and data support was provided by Rebecca Broadhurst and Joanne Wilson. Pharmacodynamic methodology and data support was provided by Michelle Scott and Adina Hughes.

\section{Authorship Contributions}

Participated in research design: Spender, Ferguson, Hughes, Davies, Goldberg, Herrera, Sansom, Barry, Inman.

Conducted experiments: Spender, Ferguson, Hughes, Davies, Goldberg, Herrera, Taylor, Strathearn, Barry, Inman.

Performed data analysis: Spender, Ferguson, Hughes, Davies, Herrera, Taylor, Barry, Inman.

Wrote or contributed to the writing of the manuscript: Spender, Hughes, Davies, Goldberg, Herrera, Taylor, Sansom, Barry, Inman.

\section{References}

Akhurst RJ and Hata A (2012) Targeting the TGF $\beta$ signalling pathway in disease Nat Rev Drug Discov 11:790-811. 
Anderton MJ, Mellor HR, Bell A, Sadler C, Pass M, Powell S, Steele SJ, Roberts RR, and Heier A (2011) Induction of heart valve lesions by small-molecule ALK5 inhibitors. Toxicol Pathol 39:916-924.

Anido J, Sáez-Borderías A, Gonzàlez-Juncà A, Rodón L, Folch G, Carmona MA, Prieto-Sánchez RM, Barba I, Martínez-Sáez E, Prudkin L, et al. (2010) TGF- $\beta$ receptor inhibitors target the CD44(high)/Id1(high) glioma-initiating cell population in human glioblastoma. Cancer Cell 18:655-668.

Blobe GC, Schiemann WP, and Lodish HF (2000) Role of transforming growth factor beta in human disease. N Engl J Med 342:1350-1358.

Bogdan S and Klämbt C (2001) Epidermal growth factor receptor signaling. Curr Biol 11:R292-R295.

Davis RJ (2000) Signal transduction by the JNK group of MAP kinases. Cell 103 239-252

Dennler S, Itoh S, Vivien D, ten Dijke P, Huet S, and Gauthier JM (1998) Direct binding of Smad3 and Smad4 to critical TGF beta-inducible elements in the promoter of human plasminogen activator inhibitor-type 1 gene. $E M B O J \mathbf{1 7}$ 3091-3100.

Fujiwara Y, Nokihara H, Yamada Y, Yamamoto N, Sunami K, Utsumi H, Asou H, TakahashI O, Ogasawara K, Gueorguieva I, et al. (2015) Phase 1 study of galunisertib, a TGF-beta receptor I kinase inhibitor, in Japanese patients with advanced solid tumors. Cancer Chemother Pharmacol 76:1143-1152.

Gellibert F, de Gouville AC, Woolven J, Mathews N, Nguyen VL, Bertho-Ruault C, Patikis A, Grygielko ET, Laping NJ, and Huet S (2006) Discovery of 4-\{4-[3-(pyridin-2yl)-1H-pyrazol-4-yl]pyridin-2-yl\}-N-(tetrahydro-2H- pyran-4-yl)benzamide (GW788388): a potent, selective, and orally active transforming growth factor-beta type I receptor inhibitor. J Med Chem 49:2210-2221.

Goldberg FW, Ward RA, Powell SJ, Debreczeni JE, Norman RA, Roberts NJ, Dishington AP, Gingell HJ, Wickson KF, and Roberts AL (2009) Rapid generation of a high quality lead for transforming growth factor-beta (TGF-beta) type I receptor (ALK5). J Med Chem 52:7901-7905.

Herbertz S, Sawyer JS, Stauber AJ, Gueorguieva I, Driscoll KE, Estrem ST, Cleverly AL, Desaiah D, Guba SC, Benhadji KA, et al. (2015) Clinical development of galunisertib (LY2157299 monohydrate), a small molecule inhibitor of transforming growth factor-beta signaling pathway. Drug Des Devel Ther 9 : 4479-4499.

Herrera B and Inman GJ (2009) A rapid and sensitive bioassay for the simultaneous measurement of multiple bone morphogenetic proteins. Identification and quantification of BMP4, BMP6 and BMP9 in bovine and human serum. BMC Cell Biol 10:20.

Inman GJ (2011) Switching TGF $\beta$ from a tumor suppressor to a tumor promoter. Curr Opin Genet Dev 21:93-99.

Inman GJ, Nicolás FJ, Callahan JF, Harling JD, Gaster LM, Reith AD, Laping NJ, and Hill CS (2002) SB-431542 is a potent and specific inhibitor of transforming growth factor-beta superfamily type I activin receptor-like kinase (ALK) receptors ALK4, ALK5, and ALK7. Mol Pharmacol 62:65-74.

Kovacs RJ, Maldonado G, Azaro A, Fernández MS, Romero FL, Sepulveda-Sánchez JM, Corretti M, Carducci M, Dolan M, Gueorguieva I, et al. (2015) Cardiac safety of TGF- $\beta$ receptor I kinase inhibitor LY2157299 monohydrate in cancer patients in a first-in-human dose study. Cardiovasc Toxicol 15:309-323.

Lahn M, Kloeker S, and Berry BS (2005) TGF-beta inhibitors for the treatment of cancer. Expert Opin Investig Drugs 14:629-643.

Levy L and Hill CS (2005) Smad4 dependency defines two classes of transforming growth factor beta (TGF-beta) target genes and distinguishes TGF-beta-induced epithelial-mesenchymal transition from its antiproliferative and migratory responses. Mol Cell Biol 25:8108-8125.

Lim $\mathrm{H}$ and $\mathrm{Zhu} \mathrm{YZ}$ (2006) Role of transforming growth factor-beta in the progression of heart failure. Cell Mol Life Sci 63:2584-2596.

Luangmonkong T, Suriguga S, Bigaeva E, Boersema M, Oosterhuis D, de Jong KP, Schuppan D, Mutsaers HAM, and Olinga P (2017) Evaluating the antifibrotic potency of galunisertib in a human ex vivo model of liver fibrosis. $\mathrm{Br} J$ Pharmacol 174:3107-3117.

Maier A, Peille AL, Vuaroqueaux V, and Lahn M (2015) Anti-tumor activity of the TGF- $\beta$ receptor kinase inhibitor galunisertib (LY2157299 monohydrate) in patientderived tumor xenografts. Cell Oncol (Dordr) 38:131-144.

Maurantonio M, Ballestri S, Odoardi MR, Lonardo A, and Loria P (2011) Treatment of atherogenic liver based on the pathogenesis of nonalcoholic fatty liver disease: a novel approach to reduce cardiovascular risk? Arch Med Res 42:337-353.

Park JH, Ryu SH, Choi EK, Ahn SD, Park E, Choi KC, and Lee SW (2015a) SKI2162, an inhibitor of the TGF- $\beta$ type I receptor (ALK5), inhibits radiation-induced fibrosis in mice. Oncotarget 6:4171-4179.

Park SA, Kim MJ, Park SY, Kim JS, Lee SJ, Woo HA, Kim DK, Nam JS, and Sheen YY (2015b) EW-7197 inhibits hepatic, renal, and pulmonary fibrosis by blocking TGF- $\beta$ /Smad and ROS signaling. Cell Mol Life Sci 72:2023-2039.

Peñuelas S, Anido J, Prieto-Sánchez RM, Folch G, Barba I, Cuartas I, García-Dorado D, Poca MA, Sahuquillo J, Baselga J, et al. (2009) TGF-beta increases gliomainitiating cell self-renewal through the induction of LIF in human glioblastoma. Cancer Cell 15:315-327.

Ramachandran A, Vizán P, Das D, Chakravarty P, Vogt J, Rogers KW, Müller P, Hinck AP, Sapkota GP, and Hill CS (2018) TGF- $\beta$ uses a novel mode of receptor activation to phosphorylate SMAD1/5 and induce epithelial-to-mesenchymal transition. eLife 7 .

Schmierer B and Hill CS (2007) TGFbeta-SMAD signal transduction: molecular specificity and functional flexibility. Nat Rev Mol Cell Biol 8:970-982.

Serova M, Tijeras-Raballand A, Dos Santos C, Albuquerque M, Paradis V, Neuzillet C, Benhadji KA, Raymond E, Faivre S, and de Gramont A (2015) Effects of TGFbeta signalling inhibition with galunisertib (LY2157299) in hepatocellular carcinoma models and in ex vivo whole tumor tissue samples from patients. Oncotarget 6:21614-21627.

Shaw R, Miller S, Curwen J, and Dymond M (2017) Design, analysis and reporting of tumor models. Lab Animal 46:207-211.

Shi Y and Massagué J (2003) Mechanisms of TGF-beta signaling from cell membrane to the nucleus. Cell 113:685-700.

Spender LC, Ferguson GJ, Liu S, Cui C, Girotti MR, Sibbet G, Higgs EB, Shuttleworth MK, Hamilton T, Lorigan P, et al. (2016) Mutational activation of BRAF confers sensitivity to transforming growth factor beta inhibitors in human cancer cells. Oncotarget 7:81995-82012.

Sridurongrit S, Larsson J, Schwartz R, Ruiz-Lozano P, and Kaartinen V (2008) Signaling via the Tgf-beta type I receptor Alk5 in heart development. Dev Biol $\mathbf{3 2 2}$ 208-218.

Vogt J, Traynor R, and Sapkota GP (2011) The specificities of small molecule inhibitors of the TGF $\beta$ and BMP pathways. Cell Signal 23:1831-1842.

Wang RN, Green J, Wang Z, Deng Y, Qiao M, Peabody M, Zhang Q, Ye J, Yan Z, Denduluri S, et al. (2014) Bone Morphogenetic Protein (BMP) signaling in development and human diseases. Genes Dis 1:87-105.

Yingling JM, McMillen WT, Yan L, Huang H, Sawyer JS, Graff J, Clawson DK, Britt KS, Anderson BD, Beight DW, et al. (2017) Preclinical assessment of galunisertib (LY2157299 monohydrate), a first-in-class transforming growth factor- $\beta$ receptor type I inhibitor. Oncotarget 9:6659-6677.

Zavadil J, Bitzer M, Liang D, Yang YC, Massimi A, Kneitz S, Piek E, and Bottinger EP (2001) Genetic programs of epithelial cell plasticity directed by transforming growth factor-beta. Proc Natl Acad Sci USA 98:6686-6691.

Zhang YE (2009) Non-Smad pathways in TGF-beta signaling. Cell Res 19:128-139.

Address correspondence to: Gareth J. Inman, Cancer Research UK Beatson Institute, Garscube Estate, Swithcback Road, Bearsden, Glasgow G61 1BD, UK. E-mail: g.inman@beatson.gla.ac.uk 